\title{
Situational Analysis of the Production of Milk and Cheese in Several Productive Sectors of Ecuador and Its Quality Under Ecuadorian NTE INEN Regulations
}

I International Seminar of Livestock and Agroindustrial Production ESPOCH 2020

Corresponding Author:

Eder Lenin Cruz Siguenza

edercruzsiguenza@gmail.com

Published: 2 September 2021

Production and Hosting by Knowledge E

(c) Eder Lenin Cruz Siguenza et al. This article is distributed under the terms of the Creative Commons Attribution License, which permits unrestricted use and redistribution provided that the original author and source are credited.

\section{Análisis Situacional de la Producción de Leche y Quesos en Varios Sectores Productivos del Ecuador y su Calidad Bajo Normativas Ecuato- rianas NTE INEN}

\author{
Eder Lenin Cruz Siguenza ${ }^{1}$, Gloria Elizabeth Miño Cascante ${ }^{2}$, Fabián Eduardo \\ Bastidas Alarcón ${ }^{3}$, and Mónica Patricia Cruz Siguenza ${ }^{4}$ \\ ${ }^{1}$ Facultad de Mecánica, Escuela de Ingeniería Automotriz, Guayaquil, Ecuador \\ ${ }^{2}$ Facultad de Mecánica, Escuela de Ingeniería Industrial, Santa Fe, Argentina \\ ${ }^{3}$ Facultad de Mecánica, Escuela de Ingeniería Mecánica \\ ${ }^{4}$ Cotesa Trading Co. - Ecuador Escuela Superior Politécnica de Chimborazo Grupo de \\ Investigación GISAI -ESPOCH
}

\section{Abstract}

Nationwide there are higher levels of dairy product consumption compared to eight years ago, when the production of dairy products was sectorized in several provinces. This has spread around the country either by hand or on an industrial level. Some of the most outstanding include Carchi, Imbabura, Pichincha, Cotopaxi, Tungurahua, Bolívar and Chimborazo. Other southern ones include Cañar, Azuay and Loja. Most of the production, trade, and industrialization of milk and its derivatives has been developed in these mountain areas, which have similar climatic characteristics. Current regulations are not complied with in many of these sectors. The public regulatory institutions include INEN (Ecuadorian Standardization Service), ARCSA (Agency for Sanitary Regulation and Control), AGROCALIDAD, MIPRO (Ministry of Industry and Productivity, SRI (Internal Revenue Services), MT (Ministry of Labor), GAD's (Decentralized Autonomous Governments); these work to ensure the well-being of consumers Minimum compliance of the regulations must be obtained for legal and sanitary operation. The minimum technical regulations specified for cheeses that artisans must comply with are the PCH's, HACCP and the BPM's. Micro, Small, and Medium-sized Enterprises (MSMEs) are common in rural areas, which often lack important factors, such as basic services, adequate education, road systems, and proper facilities for industrialization. The COVID-19 pandemic makes the future even more uncertain and an accentuated crisis will persist for many years in Ecuador.

Keywords: quality, Covid 19, INEN, milk, production.

\section{Resumen}

Existe un alto consumo de Lácteos a nivel nacional con relación hace ocho años, donde la producción de dicho producto era sectorizada en varias provincias. Esto se ha extendido alrededor del país ya sea artesanalmente o a nivel industrial. Siendo entre las más destacadas: 
'Carchi, Imbabura, Pichincha, Cotopaxi, Tungurahua, Bolívar y Chimborazo, y los demás australes de: Cañar, Azuay y Loja. En estas zonas de la serranía, con sus características climáticas similares, es donde se ha desarrollado la mayor parte de la producción, comercio, e industrialización de la leche y sus derivados. en muchos de estos sectores no se cumple con las normativas vigentes, para ello existen instituciones públicas reguladoras como son INEN (Servicio Ecuatoriano de Normalización), ARCSA (Agencia de Regulación y Control Sanitario), AGROCALIDAD, MIPRO (Ministerio de Industrias y Productividad, SRI (Servicios de Rentas Internas), MT (Ministerio del Trabajo), GAD's (Gobiernos Autónomos Descentralizados), las cuales deben velar por el bienestar de los consumidores, dichas normativas son de cumplimiento mínimo que deben obtener para el funcionamiento legal, y sanitario, en cuanto a normativas técnicas especificadas para los quesos siendo las mínimas para los Artesanos las PCH's, HACCP y las BPM's para las MIPYMES (Micro, Pequeñas, y Medianas Empresas), La mayor cantidad de empresas están asentadas en las zonas rurales, donde carecen entre muchas factores, entre las más importantes son servicios básicos, educación adecuada, sistemas viales, instalaciones adecuadas propias para la industrialización. Lo cual hace un futuro más incierto después de que la pandemia COVID 19 deje una crisis acentuada por muchos años en Ecuador.

Palabras Clave: calidad, Covid 19, INEN, leche, producción.

\section{Introducción}

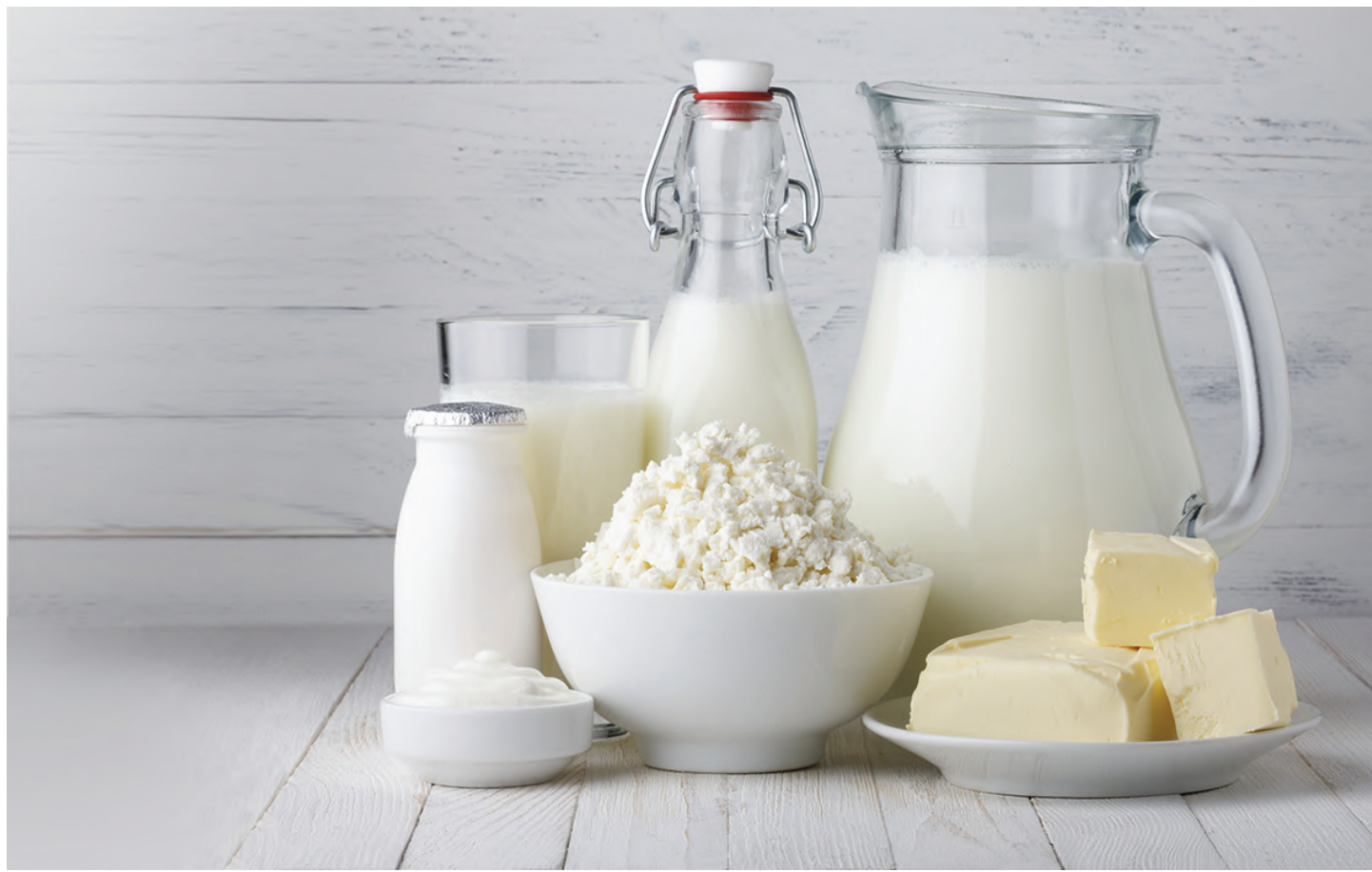

Figure 1

Leche y sus derivados (Queso). Fuente: https://www.publicayo.com/productos-lacteos/ Elaborado: Autores. 
La leche de vaca es considerada el alimento por excelencia dada su composición química en la que se encuentran todos los macronutrientes y gran cantidad de micronutrientes. El contenido de dichos componentes, aunado a la amplia gama de derivados y eficiencia en los procesos de transformación, hacen de la leche un producto de mucha demanda, que aumenta si dichos elementos constitutivos son de elevada calidad, lo que influye directamente en las características sensoriales, organolépticas y fisicoquímicas de los productos obtenidos y en el precio de venta. Las características de la leche cruda son fundamentales a la hora de obtener productos derivados como leche pasteurizada, descremada, deslactosada, ultra pasteurizada, queso, yogurt, kumis, entre otros; motivo por el cual, se considera de suma importancia que el porcentaje de grasa, proteína y sólidos no grasos sea alto y constante [1].

Por los años de 1557 llegan las primeras cabezas de ganado al Ecuador, que de acuerdo a Historiadores fueron introducidas por conquistadores especialmente por Benalcázar que fue 'acomodado ganadero en Nicaragua, de donde trae los primeros vacunos hasta Guayaquil, De ahí a la actualidad el Ecuador es un país altamente productor de ganado y lácteos. En muchos sectores la producción de leche se da en extensas explanadas y con ello se logra una industrialización uniforme de productos lácteos 2]. La industria lechera en Ecuador inició en 1950, gracias a la tecnificación de nuevos sistemas de ordeño y cuando entró en producción el ganado y crías se importaron años posteriores. Así lo relata el libro La Leche del Ecuador, publicado en el 2015 por la CIL. En los últimos 60 años la industria ha evolucionado, a tal punto que, al cierre del año precedente, el sector vendió USD 909 millones según datos proporcionados por este gremio que agrupa a Nestlé, Alpina, Reyleche, Floralp y Toni [3].

\section{Table 1}

Existencia de Ganado y producción de leche en Ecuador.

\begin{tabular}{|l|r|r|r|}
\hline & \multicolumn{1}{|c|}{2015} & \multicolumn{1}{c|}{2016} & \multicolumn{1}{c|}{2017} \\
\hline No. cabezas de ganado & $1^{\prime} 941.731$ & $2^{\prime} 042.144$ & $2^{\prime} 048.097$ \\
\hline Vacas ordeñadas & 860.886 & 896.170 & 856.164 \\
\hline Producción de leche & $4^{\prime} 982.370$ & $5^{\prime} 319.288$ & $5^{\prime} 135.405$ \\
\hline
\end{tabular}

Fuente: INEC. Elaborado: INEC.

En Chimborazo está muy fragmentada en pequeñas Unidades de Producción Agropecuaria o UPAs y tan solo el $4 \%$ son haciendas que sobrepasan las 20 hectáreas. Teniendo una producción en todos los cantones de la Provincia se produce más de 
430.000 L diarios de leche cruda, que representa un $8 \%$ de la producción nacional diaria, con un rendimiento de 6,7 L por vaca y por día. Las UPA's, hacen que la industrialización de la leche se dificulte en el aspecto de calidad e inocuidad alimentaria y factores de productividad como provincia frente a otras, Además de contar con otro factor muy importante que es la poca o nula educación en algunos casos en los campesinos de la provincia, siendo datos de analfabetismo de los cantones de la provincia, los cuales son: Alausí 25,0\%, Chambo 11,7\%, Chunchi 21,7\%, Colta 26,7, Cumandá 8,8\%, Guamote 20,1\%, Guano 10,8\%, Pallatanga 15,9\%, Penipe 9,7\%, Riobamba $8,3 \%$, tomando en cuenta que la edad promedio es de 29 años, de acuerdo a los datos tomados en el último censo en el 2010 por el INEC. Por lo que nos podemos dar cuenta que existe una gran cantidad de mano de obra no calificada para la elaboración de los Quesos siendo en donde existe el mayor porcentaje de analfabetismo donde más se produce este producto. Debemos tener en cuenta también a la pobreza que sabemos que, 'se considera a una persona pobre por ingresos si percibe un ingreso familiar per cápita menor a USD 83,79 mensuales y pobre extremo si percibe menos de USD 47,22' 4].

Detro del analisis debemos observar que los indices de pobreza con los bajos niveles de educación hacen que exista una producción de leche y sus derivados con bajos estandares de calidad, datos como estos se pudo constatar en la provincia de Cotopaxi unas de las principales en la produccion de leche en donde existe gran cantidad de fabraica artesanales de quesos. Una de las características constantes de la población rural de Cotopaxi es que su principal actividad productiva es la agricultura; lo cual evidentemente se debe a las pocas oportunidades de ocupación pro-ductiva en los territorios rurales de la provincia. Esto se complementa con el nivel bajo de instrucción de la población, especialmente del sector de la PEA, para completar una situación restrictiva de las posibilidades de acceso a empleo de calidad (si hubiera oferta) y generación de iniciativas de autodesarrollo en el sector rural de la provincia de Cotopaxi. En promedio para las 33 parroquias rurales en estudio, se encontró que 66,9; 67,8 y 60,8\% de la población se dedicaba a la agricultura en los años 1990, 2001 y 2010 , respectivamente; mientras que hubo parroquias cuya población dedicada a agricultura superó el 90\% (Tabla 2). Adicionalmente, se encontró que en las parroquias donde la población prevalente es indígena, las proporciones de la población dedicada a la agricultura son las más altas, así: Angamarca (79\%), Chugchilán (82\%), Cochapamba (84\%), Pilaló (60\%), Guangaje (79\%), Isinliví (79\%), Moraspungo (79\%), Pinllopata (91\%), Ramón Campaña (71\%), Toacaso (73\%) y Zumbahua (73\%), las cuales, como se mencionó, coincidentemente presentan los más altos niveles de pobreza. Por otra parte, se encontró que el nivel de instrucción de la población rural estudiada es visiblemente bajo. El $42 \%$ de la población tiene apenas instrucción básica de nivel primario; el 37\% de la población ha cursado el nivel secundario, y solamente el $5 \%$ ha cursado el nivel superior (universitario); mientras que el analfabetismo todavía prevalece hasta en un 15\%, en promedio de la población, en las 33 parroquias rurales estudiadas [5]. Nuevamente, las parroquias rurales que muestran la mayoría de población indígena, también muestran los mayores niveles de analfabetismo, ejemplo: Angamarca (30,1\%); Chugchilán (21,5\%); Cochapamba (22,6\%); Guangaje (30,8\%); Isinlibí (21,5\%); Pilaló (22,5\%); Ramón Campaña $(20,1 \%)$ y Zumbahua $(29,2 \%)$. En estas circunstancias, evidentemente las posibilidades 
de desarrollo o de auto desarrollo de las poblaciones en estudio son limitadas, aun cuando la disponibilidad de recursos y las oportunidades fueran de las mejores [6].

Algo similar sucede en sectores de la region costa donde ademas de existir la pobreza en las zonas rurales, esta presente la migracion hacia las cuidades asi como al exterior, con ellos presentandoce un indice mas alto en el deficit de una produccion lechera y de productos derivados en estos sectores. $Y$ cada vez se incrementa esta problemática sabiendo que en las zonas rurales o conocido como el campo es donde se produce la leche cruda fuente primaria de los derivados. 'En primer lugar es trascendental saber las razones por las que emigraron y las respuestas fueron que en un $60 \%$ lo hicieron por trabajo, $12,5 \%$ en busca de educación media, una vez terminada la primaria o superior. El 11,9\% salió por no encontrarse conforme con las condiciones de vida en el campo, mientras que un $7 \%$ lo hizo para reencontrarse con los familiares que habían salido anteriormente. De acuerdo a estas respuestas, se mantiene que la emigración nacional e internacional, rural o urbana, el principal motivo es la búsqueda de trabajo, ya sea por el desempleo o por mejorar los ingresos en otro lugar. Hay que anotar que, según los datos del INEC, en 2014 el desempleo rural se ubicó en 2,3\% a nivel nacional y para la provincia de Los Ríos la media de desempleo entre urbano y rural en 2015 se encontraba en 4,99\% (Tomado de diario 'La Hora' de 22 de septiembre de 2015). Esto indica que la emigración rural de la provincia no se debió a la falta de empleo, sino a la búsqueda de una mejora de las condiciones laborales y de remuneración que podrían conseguir en la ciudad o en otro país, ya que los ingresos de la actividad agrícola han sido históricamente bajos e insuficientes para tener una vida con mínimas comodidades, otra causa, que según los encuestados manifestaron, fue la de la inconformidad con las condiciones de vida que tienen en los sectores rurales. En estos lugares se encuentran carencias como los servicios básicos que sí hay en las ciudades (agua potable y entubada, alcantarillado, luz eléctrica, internet, etc.), centro médicos y educativos de segundo y tercer nivel, centros de diversión, entre otros. Como se sabe, las condiciones de vida está ligada a la renta y en el campo, como se ha dicho, es muy baja, pues la actividad agrícola depende del mercado y condiciones climáticas, y las actividades comerciales en estos sectores, sólo en pocos casos son lucrativas [7].

\section{Metodología}

Existen muchas normas INEN que normas de calidad propias del Ecuador que desde la produccion de leche Cruda y sus requisitos, asi como la fabricacion de derivados que en este caso se ha tomado la de los quesos, existe un sinmuero de igualmanera de Normas para este tipo de producto pero se ha tomado de los productos que mas se fabrican en el Ecuador, la mayoria de los parametros que los productores de queso y leche que manejan en varias zonas del Ecuador se desctibe a continuacion, como metodologia de guianza para el manejo de la calidad del producto. 


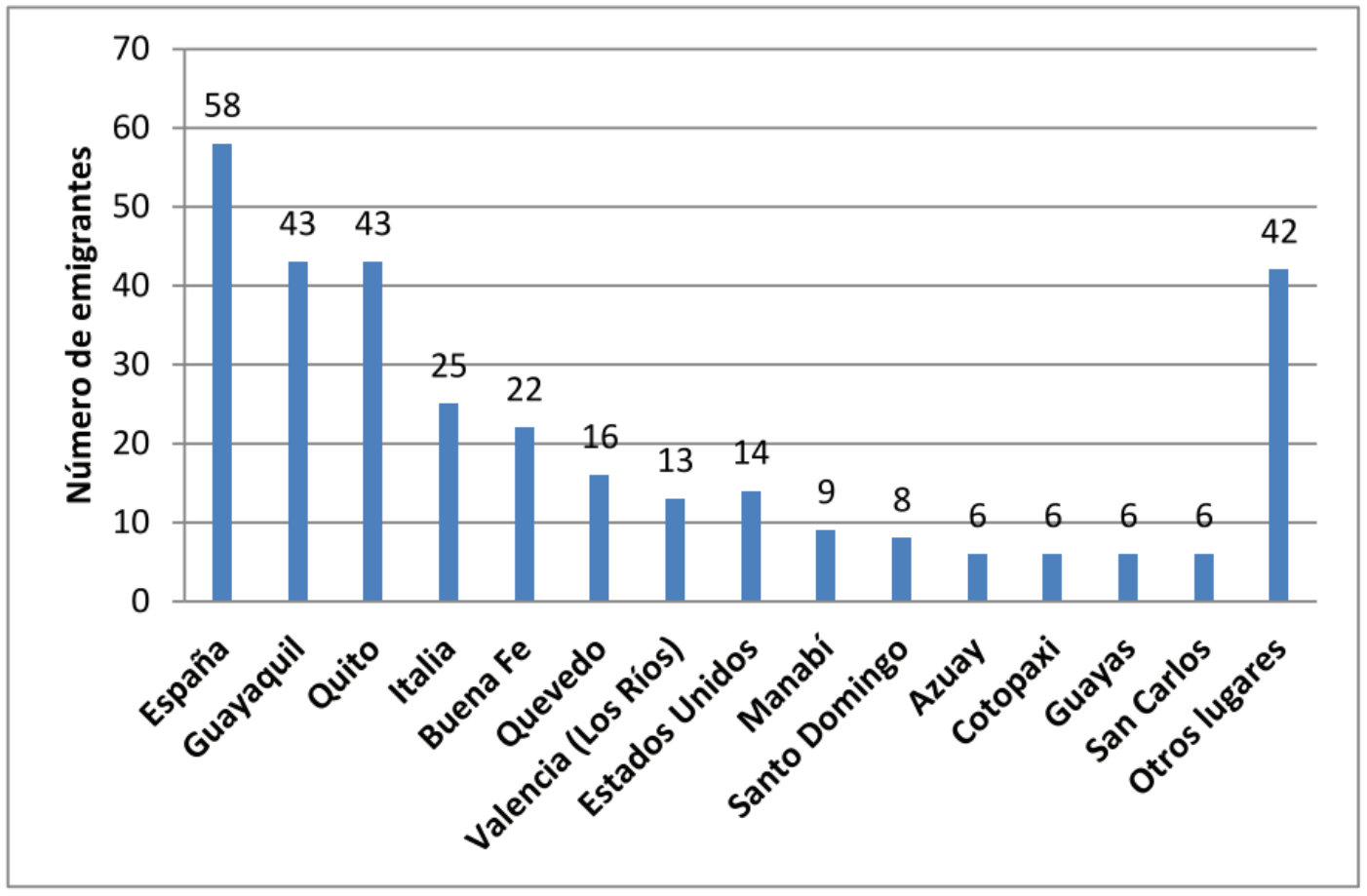

Figure 2

Residencia de emigrantes de productores rurales de la provincia de los Rios. Fuente: Referencia [7]. Elaborado por: Figueredo, Lorenzo.

\subsection{Leche cruda requisitos NTE INEN 9:2012}

Leche que no ha sido sometida a ningún tipo de calentamiento, es decir su temperatura no ha superado la de la leche inmediatamente después de ser extraída de la ubre (no más de $40^{\circ} \mathrm{C}$ ) [8].

\subsection{Leche cruda. Determinación de la adulteración. Métodos de ensayo cualitativos NTE INEN 1500}

Para validar este termino deberos conocer que la adulteracion de la leche cruda es el Acto por el cual se altera la leche cruda, siendo privada en forma parcial o total, de sus elementos útiles o característicos, reemplazándolos o no, por otros inertes o extraños de cualquier naturaleza, para disimular u ocultar alteraciones o calidad deficiente [9].

\subsection{Leche pasteurizada requisitos NTE INEN 10:2012}

Es la leche cruda homogenizada o no, que ha sido sometida a un proceso térmico que garantice la destrucción total de los microorganismos patógenos y la casi totalidad de los microorganismos banales (saprofitos) sin alterar sensiblemente las características fisicoquímicas, nutricionales y organolépticas de la misma [10]. 
Table 2

Requisitos fisicoquímicos de la leche cruda.

\begin{tabular}{|c|c|c|c|c|}
\hline REQUISITOS & UNIDAD & MIN. & MAX. & MÉTODO DE ENSAYO \\
\hline $\begin{array}{l}\text { Densidad relativa: } \\
\text { a } 15^{\circ} \mathrm{C} \\
\text { A } 20^{\circ} \mathrm{C} \\
\end{array}$ & - & $\begin{array}{l}1,029 \\
1,028 \\
\end{array}$ & $\begin{array}{l}1,033 \\
1,032 \\
\end{array}$ & NTE INEN 11 \\
\hline Materia grasa & $\begin{array}{l}\% \text { (fracción } \\
\text { de masa) }\end{array}$ & 3,0 & - & NTE INEN 12 \\
\hline Acidez titulable como ácido láctico & $\begin{array}{l}\% \text { (fracción } \\
\text { de masa) }\end{array}$ & 0,13 & 0,17 & NTE INEN 13 \\
\hline Sólidos totales & $\begin{array}{l}\% \text { (fracción } \\
\text { de masa) }\end{array}$ & 11,2 & - & NTE INEN 14 \\
\hline Sólidos no grasos & $\begin{array}{l}\text { \% (fracción } \\
\text { de masa) }\end{array}$ & 8,2 & - & * \\
\hline Cenizas & $\begin{array}{l}\% \text { (fracción } \\
\text { de masa) }\end{array}$ & 0,65 & - & NTE INEN 14 \\
\hline $\begin{array}{l}\text { Punto de congelación } \\
\text { (punto crioscópico) }{ }^{\star *}\end{array}$ & ${ }^{\circ} \mathrm{C}$ & $\begin{array}{l}-0,536 \\
-0,555\end{array}$ & $\begin{array}{l}-0,512 \\
-0,530\end{array}$ & NTE INEN 15 \\
\hline Proteínas & $\begin{array}{l}\% \text { (fracción } \\
\text { de masa) }\end{array}$ & 2,9 & - & NTE INEN 16 \\
\hline Ensayo de reductasa (azul de metileno) & $\mathrm{h}$ & 3 & - & NTE INEN 018 \\
\hline $\begin{array}{l}\text { Reacción de estabilidad proteica (prueba } \\
\text { de alcohol) }\end{array}$ & $\begin{array}{l}\text { Para leche de } \\
\text { por la adición } \\
68 \% \text { en peso } \\
\text { destinada a ul } \\
\text { adición de un } \\
\text { en peso o } 78 \\
\end{array}$ & $\begin{array}{l}\text { da a pateu } \\
\text { In volumen } \\
\% \text { en volu } \\
\text { asteurizacic } \\
\text { men igual } \\
\text { volumen }\end{array}$ & $\begin{array}{l}\text { ón: No se coagulará } \\
\text { de alcohol neutro de } \\
\text { y para la leche } \\
\text { se coagulará por la } \\
\text { ohol neutro de } 71 \%\end{array}$ & NTE INEN 1500 \\
\hline Presencia de conservantes ${ }^{11}$ & - & Negativo & & NTE INEN 1500 \\
\hline Presencia de neutralizantes ${ }^{21}$ & - & Negativo & & NTE INEN 1500 \\
\hline Presencia de adulterantes $^{3}$ & - & Negativo & & NTE INEN 1500 \\
\hline Grasas vegetales & - & Negativo & & NTE INEN 1500 \\
\hline Suero de Leche & - & Negativo & & NTE INEN 2401 \\
\hline Prueba de Brucelosis & - & Negativo & & $\begin{array}{l}\text { Prueba de anillo PAL (Ring } \\
\text { Test) }\end{array}$ \\
\hline $\begin{array}{l}\text { RESIDUOS DE MEDICAMENTOS } \\
\text { VETERINARIOS }{ }^{5} \text { ) }\end{array}$ & ug/l & -- & $\begin{array}{l}\text { MRL, establecidos } \\
\text { en el CODEX } \\
\text { Alimentarius } \\
\text { CAC/MRL } 2\end{array}$ & $\begin{array}{l}\text { Los establecidos en el } \\
\text { compendio de métodos de } \\
\text { análisis identificados como } \\
\text { idóneos para respaldar los } \\
\text { LMR del codex }\end{array}$ \\
\hline \multicolumn{5}{|c|}{$\begin{array}{l}\text { Diferencia entre el contenido de sólidos totales y el contenido de grasa. } \\
\text { ** } \mathrm{C}=\mathrm{H} \cdot \mathrm{f} \text {, donde } \mathrm{f}=0,9656 \\
* \text { Aplicable a la leche cruda antes de ser sometida a enfriamiento } \\
\text { 1) Conservantes: formaldehido, peróxido de hidrógeno, cloro, hipocloritos, cloraminas, lactoperoxidosa adicionada y dióxido de cloro. } \\
\text { 2) Neutralizantes: orina, carbonatos, hidróxido de sodio, jabones. } \\
\text { 3) Adulterantes: Harina y almidones, soluciones azucaradas o soluciones salinas, colorantes, leche en polvo, suero de leche, grasas vegetales. } \\
\text { 4) "Fracción de masa de } \mathrm{B}, \mathrm{W}_{\mathrm{B}} \text { : Esta cantidad se expresa frecuentemente en por ciento, \%. La notación "\% }(\mathrm{m} / \mathrm{m})^{\text {" }} \text { no deberá usarse". } \\
\text { 5) Se refiere a aquellos medicamentos veterinarios aprobados para uso en ganado de producción lechera. } \\
\text { 6) Establecidos por el comité del Codex sobre residuos de medicamentos veterinarios en los alimentos }\end{array}$} \\
\hline
\end{tabular}

NOTA 1. Se podrán presentar variaciones en estas características, en función de la raza, estación climática o alimentación, pero estas no deben afectar significativamente las características sensoriales indicadas.

Fuente: Referencia [8].

Elaborado: INEN.

\subsection{Norma general para quesos frescos no madurados. Requisitos NTE INEN 1528:2012}

Queso. Se entiende por queso el producto blando, semiduro, duro y extra duro, madurado o no madurado, y que puede estar recubierto, en el que la proporción entre las proteínas de suero y la caseína no sea superior a la de la leche, obtenido mediante: (a) Coagulación total o parcial de la proteína de la leche, leche descremada, leche parcialmente descremada, crema, crema de suero o leche, de mantequilla o de cualquier combinación de estos ingredientes, por acción del cuajo u otros coagulantes idóneos, y por escurrimiento parcial del suero que se desprende como consecuencia 
Table 3

Limites maximo para contaminantes.

\begin{tabular}{|l|c|c|}
\hline \multicolumn{1}{|c|}{ Requisito } & Límite máximo (LM) & Método de ensayo \\
\hline Plomo, $\mathrm{mg} / \mathrm{kg}$ & 0,02 & ISO/TS 6733 \\
\hline Aflatoxina M1, $\mu \mathrm{g} / \mathrm{kg}$ & 0,5 & ISO 14674 \\
\hline
\end{tabular}

Fuente: Referencia [8].

Elaborado: INEN.

\section{Table 4}

Requisitos microbiológicos de la leche cruda tomada en Hato.

\begin{tabular}{|c|c|c|}
\hline Requisito & Limite máximo & Método de ensayo \\
\hline $\begin{array}{l}\text { Recuento de microorganismos } \\
\text { aeróbios mesófilos REP, UFC/cm }\end{array}$ & $1,5 \times 10^{6}$ & NTE INEN 1529:-5 \\
\hline $\begin{array}{l}\text { Recuento de células } \\
\text { somáticas } / \mathrm{cm}^{3}\end{array}$ & $7,0 \times 10^{5}$ & AOAC -978.26 \\
\hline
\end{tabular}

Fuente: Referencia [8].

Elaborado: INEN.

Table 5

Reaciones de los diferentes ensayos para detectar la concentración de cloro libre.

\begin{tabular}{|c|c|c|c|c|c|c|}
\hline Prueba & \multicolumn{7}{|c|}{ Concentración de cloro libre } \\
\cline { 2 - 7 } & $\mathbf{1 : 1 0 0 0}$ & $\mathbf{1}: \mathbf{2 0 0 0}$ & $\mathbf{1}: \mathbf{5 0 0 0}$ & $\mathbf{1 : 1 0 0 0 0}$ & $\mathbf{1 : 2 5 0 0 0}$ & $\mathbf{1 : 5 0 0 0 0}$ \\
\hline Ensayo I & $\begin{array}{c}\text { Marrón } \\
\text { amarillento }\end{array}$ & $\begin{array}{c}\text { Amarillo } \\
\text { oscuro }\end{array}$ & $\begin{array}{c}\text { Amarillo } \\
\text { pálido }\end{array}$ & - & - & - \\
\hline Ensayo II & $\begin{array}{c}\text { Marrón } \\
\text { amarillento }\end{array}$ & $\begin{array}{c}\text { Amarillo } \\
\text { oscuro }\end{array}$ & $\begin{array}{c}\text { Amarillo } \\
\text { claro }\end{array}$ & - & - & - \\
\hline Ensayo III & $\begin{array}{c}\text { Marrón } \\
\text { amarillento }\end{array}$ & $\begin{array}{c}\text { Amarillo } \\
\text { oscuro }\end{array}$ & Amarillo & Amarillo & $\begin{array}{c}\text { Amarillo } \\
\text { pálido }\end{array}$ & amarillo \\
\hline Ensayo IV & Azul-púrpura & Azul-púrpura & Azul-púrpura & $\begin{array}{c}\text { Rojo oscuro- } \\
\text { púrpura }\end{array}$ & $\begin{array}{c}\text { Rojo- } \\
\text { púrpura }\end{array}$ & $\begin{array}{c}\text { Rojo pálido - } \\
\text { púrpura }\end{array}$ \\
\hline
\end{tabular}

Fuente: Referencia [9].

Elaborado: INEN.

de dicha coagulación, respetando el principio de que la elaboración del queso resulta en una concentración de proteína láctea (especialmente la porción de caseína) y que por consiguiente, el contenido de proteína del queso deberá ser evidentemente más alto que el de la mezcla de los ingredientes lácteos ya mencionados en base a la cual se elaboró el queso; y/o b) Técnicas de elaboración que comportan la coagulación de la proteína de la leche y/o de productos obtenidos de la leche que dan un producto final que posee las mismas características físicas, químicas y organolépticas que el producto definido en el apartado a) [11]. 
Table 6

Soluciones patrón de leche con bicarbonato de sodio.

\begin{tabular}{|c|c|c|}
\hline $\begin{array}{l}\text { Balón aforado de } 100 \\
\mathrm{~mL}\end{array}$ & $\begin{array}{l}\text { Solución de bicarbonato de } \\
\text { sodio } 50 \mathrm{mg} / \mathrm{mL}\end{array}$ & $\begin{array}{l}\% \text { Bicarbonato de sodio } \\
\text { en leche cruda }\end{array}$ \\
\hline 1 & $1 \mathrm{~mL}$ & 0,05 \\
\hline 2 & $2 \mathrm{~mL}$ & 0,10 \\
\hline 3 & $3 \mathrm{~mL}$ & 0,15 \\
\hline
\end{tabular}

Fuente: Referencia [9].

Elaborado: INEN.

\subsection{Queso andino madurado requisitos, NTE INEN 2607:2012}

Es un queso semiduro, el cuerpo presenta un color que varía de marfil a amarillo claro o amarillo y tiene una textura firme (al presionarse con el dedo pulgar) que se puede cortar [12].

\subsection{Norma general para quesos de suero y quesos de proteinas de suero. Requisitos NTE INEN 2584:2013}

Queso de suero. Se entiende por queso de suero los productos sólidos, semisólidos o blandos obtenidos principalmente por medio de uno de los siguientes procesos: (a) concentración de suero y el moldeo del suero concentrado. (b) coagulación térmica del suero con la adición de ácido o sin ella.

Queso de proteínas del suero. Se entiende por queso de proteínas de suero el producto que contiene la proteína extraída del componente de suero de la leche. Estos productos se elaboran a partir de la coagulación de proteínas de suero (queso Ricotta por ejemplo); y es diferente del queso de suero [13].

\section{Desarrollo y Discusión}

\subsection{Desarrollo}

Se realizaron varios estudios de la calidad de la leche y de sus derivados especificamente de los quesos, hemos tomado en esta investigacion de revision algunas provincias y cantones del Ecuador que son reconocidos por el nivel de produccion de leche y quesos para evaluar cual es el analisis situacional de la produccion dentro de los ultimos 5 anos tomando en cuenta datos desde el el 2015 en adelante. 
Table 7

Requisitos fisicos y quimicos de la leche paseurizada.

\begin{tabular}{|c|c|c|c|c|c|c|c|c|}
\hline \multirow{2}{*}{\begin{tabular}{|l|}
\multicolumn{1}{|c|}{ REQUISITOS } \\
Densidad Relativa \\
a $15^{\circ} \mathrm{C}$ \\
a $20^{\circ} \mathrm{C}$ \\
\end{tabular}} & UNIDAD & \multicolumn{2}{|c|}{$\begin{array}{l}\text { ENTERA } \\
\text { MIN. MAX. }\end{array}$} & \multicolumn{2}{|c|}{$\begin{array}{c}\text { SEMIDESCREMADA } \\
\text { MIN. MAX. }\end{array}$} & \multicolumn{2}{|c|}{ DESCREMADA } & $\begin{array}{l}\text { MÉTODO DE } \\
\text { ENSAYO }\end{array}$ \\
\hline & - & $\begin{array}{l}1,029 \\
1,028\end{array}$ & $\begin{array}{l}1,033 \\
1,032\end{array}$ & $\begin{array}{c}1,030 \\
1,029\end{array}$ & $\begin{array}{l}1,033 \\
1,032\end{array}$ & $\begin{array}{l}1,031 \\
1,030\end{array}$ & $\begin{array}{l}1,036 \\
1,035\end{array}$ & NTE INEN 11 \\
\hline \begin{tabular}{|l|} 
Contenido de \\
grasa
\end{tabular} & $\begin{array}{l}\% \text { (fracción } \\
\text { de masa) }\end{array}$ & 3,0 & - & $\geq 1,0$ & $<3,0$ & - & $<1,0$ & NTE INEN 12 \\
\hline $\begin{array}{l}\text { Acidez titulable, } \\
\text { expresada como } \\
\text { ácido Láctico }\end{array}$ & $\begin{array}{l}\% \text { (fracción } \\
\text { de masa) }\end{array}$ & 0,13 & 0,18 & 0,13 & 0,18 & 0,13 & 0,18 & NTE INEN 13 \\
\hline Sollidos totales & $\begin{array}{c}\% \text { (fracción } \\
\text { de masa) }\end{array}$ & 11,30 & $=$ & 8,80 & 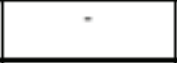 & 8,30 & 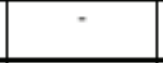 & NTE INEN 14 \\
\hline Solidos no grasos & $\begin{array}{l}\% \text { (fracción } \\
\text { de masa) }\end{array}$ & 8,30 & $\overline{7}$ & 8,20 & $\overline{7}$ & 8,20 & $\overline{7}$ & $\bar{*}$ \\
\hline Ceniza & $\begin{array}{l}\text { \% (fracción } \\
\text { de masa) }\end{array}$ & 0,65 & 0,80 & 0,70 & 0,80 & 0,70 & 0,80 & NTE INEN 14 \\
\hline 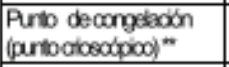 & $\begin{array}{l}{ }^{\circ} \mathrm{C} \\
{ }^{\circ} \mathrm{H} \\
\end{array}$ & $\begin{array}{l}0,536 \\
-0,555 \\
\end{array}$ & $\begin{array}{l}-0,512 \\
-0,530 \\
\end{array}$ & $\begin{array}{l}-0,536 \\
-0,555 \\
\end{array}$ & $\begin{array}{l}-0,512 \\
-0,530 \\
\end{array}$ & $\begin{array}{l}-0,536 \\
-0,555 \\
\end{array}$ & $\begin{array}{l}=0,512 \\
-0,530 \\
\end{array}$ & NTE INEN 15 \\
\hline Proteinas & $\begin{array}{l}\% \text { (fracción } \\
\text { de masa) }\end{array}$ & 2,9 & - & 2,9 & - & 2,9 & - & NTE INEN 16 \\
\hline $\begin{array}{l}\text { Ensayo de } \\
\text { fosfatasa }\end{array}$ & $\cdot$ & \multicolumn{2}{|c|}{ Negativo } & \multicolumn{2}{|c|}{ Negativo } & \multicolumn{2}{|c|}{ Negativo } & NTE INEN 19 \\
\hline \begin{tabular}{|l|} 
Ensayo de \\
Peroxidosa
\end{tabular} & $r$ & \multicolumn{2}{|c|}{ Positivo } & \multicolumn{2}{|c|}{ Positivo } & \multicolumn{2}{|c|}{ Positivo } & NTE INEN 2334 \\
\hline $\begin{array}{l}\text { Presencia de } \\
\text { conservantes }\end{array}$ & 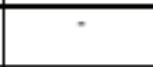 & \multicolumn{2}{|c|}{ Negativo } & \multicolumn{2}{|c|}{ Negativo } & \multicolumn{2}{|c|}{ Negativo } & NTE INEN 1500 \\
\hline $\begin{array}{l}\text { Presencia de } \\
\text { neutralizantes }{ }^{2 \text { ) }}\end{array}$ & 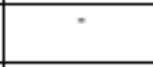 & \multicolumn{2}{|c|}{ Negativo } & \multicolumn{2}{|c|}{ Negativo } & \multicolumn{2}{|c|}{ Negativo } & NTE INEN 1500 \\
\hline \begin{tabular}{|l} 
Presencia de \\
adulterantes $^{33}$ \\
\end{tabular} & $=$ & \multicolumn{2}{|c|}{ Negativo } & \multicolumn{2}{|c|}{ Negativo } & \multicolumn{2}{|c|}{ Negativo } & NTE INEN 1500 \\
\hline Grasa Vegetal & - & \multicolumn{2}{|c|}{ Negativo } & \multicolumn{2}{|c|}{ Negativo } & \multicolumn{2}{|c|}{ Negativo } & NTE INEN 1500 \\
\hline Suero de Leche & - & \multicolumn{2}{|c|}{ Negativo } & \multicolumn{2}{|c|}{ Negativo } & \multicolumn{2}{|c|}{ Negativo } & NTE INEN 2401 \\
\hline $\begin{array}{l}\text { RESIDUOS DE } \\
\text { MEDICAMENTOS } \\
\text { VETERINARIOS }\end{array}$ & ughl & - & \begin{tabular}{l|} 
UMR \\
estableodos \\
en el CODEX \\
Aimantaius \\
CACLMR2
\end{tabular} & - & \begin{tabular}{|l|} 
LMR, \\
establecidos \\
en el CODEX \\
Alimentarius \\
CAC/MLR 2
\end{tabular} & - & \begin{tabular}{|l|} 
LMR, \\
establecidos \\
en \\
CODEX ell \\
Alimentarius \\
CAC/MLR 2
\end{tabular} & $\begin{array}{l}\text { Los establecidos } \\
\text { en el compendio } \\
\text { de métodos de } \\
\text { análisis } \\
\text { identificados } \\
\text { como idóneos } \\
\text { para respaldar } \\
\text { los LMR del } \\
\text { codex }\end{array}$ \\
\hline $\begin{array}{l}\text { Reacción de } \\
\text { estabilidad proteica } \\
\text { (prueba de alcohol) }\end{array}$ & \multicolumn{7}{|c|}{$\begin{array}{l}\text { No se coagulará por la adición de un wolumen igual de alcohol neutro de } 68 \% \text { en peso o } 75 \\
\% \text { en volumen }\end{array}$} & NTE INEN 1500 \\
\hline \multicolumn{9}{|c|}{ Cuando el producto haya sido reducido en su contenido de lactosa } \\
\hline \begin{tabular}{|l|} 
Lactosa en el \\
producto \\
parcialmente \\
deslactosado \\
\end{tabular} & $\begin{array}{l}\text { \% (fracción } \\
\text { de masa) }\end{array}$ & - & 1,4 & - & 1,4 & - & 1,4 & $\begin{array}{l}\text { AOAC } \\
\text { 984.15.15 Edc. } \\
\text { Vol. } 2\end{array}$ \\
\hline \begin{tabular}{|l} 
Lactosa en el \\
producto bajo en \\
lactosa
\end{tabular} & $\begin{array}{c}\text { \% (fracción } \\
\text { de masa) }\end{array}$ & - & 0,7 & - & 0,7 & - & 0,7 & $\begin{array}{c}\text { AOAC } \\
984.15 .15 \text { Edc. } \\
\text { Vol. } 2 \\
\end{array}$ \\
\hline
\end{tabular}

- Diferencia entre el contenido de sólidos totales y el contenido de grasa

*. $\quad \mathrm{C}={ }^{\circ} \mathrm{H}$. $f$, donde: $f=0.9656$

1) Conservantes: formaldehido, peróxido de hidrógeno, cloro, hipocloritos, cloraminas, lactoperoxidosa adicionada y dúxido de cloro.

2) Neutralizantes: orina, carbonalos, hidróxido de sodio, jabones.

3) Aduiterantes: Harina y almidones, soluciones azuceredes o soluciones salnas, colorantes, leche en polvo, suero de leche, grasas vegetales.

4) "Fracción de masa de B, $W_{\mathrm{B}}$ : Esta cantidad se expresa frecuentemente en por ciento, \%. La notación " $\%$ (m'm)" no debera usarse"

5) Se refiere a aquellos medicamentos veterinarios aprobados para uso en ganado de producción lechera.

6) Establecido por el comite del codex sobre residuos de medicamentos veterinarios en los alimentos

Fuente: Referencia [10].

Elaborado: INEN. 


\section{Table 8}

Requisitos microbiológicos de la leche pasteurizada.

\begin{tabular}{|c|c|c|c|c|c|}
\hline Requisito & $\mathbf{n}$ & m & M & c & Método de ensayo \\
\hline $\begin{array}{l}\text { Recuento de microorganismos mesófilos, } \\
\text { UFC } / \mathrm{cm}^{3}\end{array}$ & 5 & 30000 & 50000 & 1 & NTE INEN $1529-5$ \\
\hline Recuento de coliformes, UFC $/ \mathrm{cm}^{3}$ & 5 & $<1$ & 10 & 1 & AOAC 991.14 \\
\hline Detección de Listeria monocytogenes $/ 25 \mathrm{~g}$ & 5 & 0 & - & 0 & ISO 11290-1 \\
\hline Detección de Salmonella $/ 25 \mathrm{~g}$ & 5 & 0 & - & - & NTE INEN 1529-15 \\
\hline Recuento de Escherichia coli, UFC/g & 5 & $<10$ & - & 0 & AOAC 991.14 \\
\hline
\end{tabular}

Donde:

$\mathrm{n}=$ Número de muestras a examinar

$\mathrm{m}=$ Índice máximo permisible para identificar nivel de buena calidad.

$\mathrm{M}=$ Índice máximo permisible para identificar nivel aceptable de calidad.

$c=$ Número de muestras permisibles con resultados entre $\mathrm{m}$ y $\mathrm{M}$.

Fuente: Referencia [10]

Elaborado: INEN.

\section{Table 9}

Requisitos microbiológicos de la leche pasteurizada.

\begin{tabular}{|l|c|c|}
\hline \multicolumn{1}{|c|}{ Requisito } & Límite máximo (LM) & Método de ensayo \\
\hline Plomo, $\mathrm{mg} / \mathrm{kg}$ & 0,02 & ISO/TS 6733 \\
\hline Aflatoxina M1, $\mathrm{\mu g} / \mathrm{kg}$ & 0,5 & ISO 14674 \\
\hline
\end{tabular}

Fuente: Referencia [10].

Elaborado: INEN.

\section{Table 10}

Porcentajes de humedad y grasa de acuerdo a norma INEN.

\begin{tabular}{|l|c|c|}
\hline Tipo o clase & $\begin{array}{l}\text { Humedad \% max } \\
\text { NTE INEN 63 }\end{array}$ & $\begin{array}{l}\text { Contenido de grasa en extracto } \\
\text { seco \% m/m Mínimo } \\
\text { NTE INEN 64 }\end{array}$ \\
\hline Semiduro & 55 & - \\
Duro & 40 & - \\
Semiblando & 65 & - \\
Blando & 80 & - \\
Rico en grasa & - & 45 \\
Entero ó graso & - & 20 \\
Semidescremado o bajo en & - & 0,1 \\
grasa & - & \\
Descremado ó magro & - & \\
\hline
\end{tabular}

Fuente: Referencia [11].

Elaborado: INEN. 


\section{Table 11}

Requisitos microbiológicos para quesos frescos no madurados.

\begin{tabular}{|l|c|c|c|c|l|}
\hline \multicolumn{1}{|c|}{ Requisito } & $\mathbf{n}$ & $\mathbf{m}$ & $\mathbf{M}$ & $\mathbf{c}$ & \multicolumn{1}{c|}{ Método de ensayo } \\
\hline Enterobacteriaceas, UFC/g & 5 & $2 \times 10^{2}$ & $10^{3}$ & 1 & NTE INEN 1529-13 \\
\hline Escherichia coli, UFC/g & 5 & $<10$ & 10 & 1 & AOAC 991.14 \\
\hline Staphylococcus aureus UFC/g & 5 & 10 & $10^{2}$ & 1 & NTE INEN 1529-14 \\
\hline Listeria monocytogenes /25 g & 5 & ausencia & - & & ISO 11290-1 \\
\hline Salmonella en 25g & 5 & AUSENCIA & - & 0 & NTE INEN 1529-15 \\
\hline
\end{tabular}

Donde:

$\mathrm{n} \quad=$ Número de muestras a examinar.

$\mathrm{m}$ = Índice máximo permisible para identificar nivel de buena calidad.

$\mathrm{M}$ = Índice máximo permisible para identificar nivel aceptable de calidad.

$\mathrm{C}=$ Número de muestras permisibles con resultados entre $\mathrm{m}$ y $\mathrm{M}$.

Fuente: Referencia [11].

Elaborado: INEN.

Table 12

Requsitos fisicoquimicos.

\begin{tabular}{|c|c|c|c|}
\hline REQUISITO & Mín. & Max. & METODO DE ENSAYO \\
\hline $\begin{array}{l}\text { Grasa láctea en extracto seco, \% } \\
(\mathrm{m} / \mathrm{m})\end{array}$ & 35,0 & -- & NTE INEN 63 \\
\hline \multirow[t]{6}{*}{ Extracto seco: } & \multicolumn{2}{|c|}{$\begin{array}{l}\text { Según el contenido de grasa en el } \\
\text { extracto seco, de acuerdo a la siguiente } \\
\text { tabla. }\end{array}$} & NTE INEN 64 \\
\hline & \multicolumn{2}{|c|}{$\begin{array}{l}\text { Contenido de grasa en el extracto } \\
\qquad \operatorname{seco}(\mathrm{m} / \mathrm{m}) \text { : }\end{array}$} & $\begin{array}{l}\text { Contenido de extracto seco } \\
\text { mínimo correspondiente } \\
(\mathrm{m} / \mathrm{m}) \text { : }\end{array}$ \\
\hline & \multicolumn{2}{|c|}{$>30,0 \%<40,0 \%$} & $38,0 \%$ \\
\hline & \multicolumn{2}{|c|}{$>40,0 \%<48,0 \%$} & $52,0 \%$ \\
\hline & \multicolumn{2}{|c|}{$>48,0 \%<60,0 \%$} & $55,0 \%$ \\
\hline & \multicolumn{2}{|c|}{$>60,0 \%$} & $62,0 \%$ \\
\hline
\end{tabular}

Fuente: Referencia [12].

Elaborado: INEN.

\subsubsection{Analisis situacional de la producción de la Leche de acuerdo a nor- mas NTE INEN}

Se puede observar una comparación de la producción de leche entre las provincias de Cotopaxi, Tungurahua y Chimborazo. La comparación entre los años 2015 y 2017 demuestra una inestabilidad en la producción en las tres provincias. Además, en cuanto 


\section{Table 13}

Requisitos microbiológicos.

\begin{tabular}{|c|c|c|c|c|c|}
\hline Requisito & $\mathbf{n}$ & $\mathbf{m}$ & $\mathbf{M}$ & $\mathbf{c}$ & Método de ensayo \\
\hline Enterobacteriaceas, UFC/g & 5 & $2 \times 10^{2}$ & $10^{3}$ & 2 & NTE INEN 1529-13 \\
\hline Staphylococcus aureus UFC/g & 5 & $10^{2}$ & $10^{3}$ & 1 & NTE INEN 1529-14 \\
\hline
\end{tabular}

Donde:

$\mathrm{n}=$ Número de muestras a examinar.

$\mathrm{m}=$ Índice máximo permisible para identificar nivel de buena calidad.

$\mathrm{M}=$ Índice máximo permisible para identificar nivel aceptable de calidad.

$\mathrm{c}=$ Número de muestras permisibles con resultados entre $\mathrm{m}$ y $\mathrm{M}$.

Fuente: Referencia [12].

Elaborado: INEN.

\section{Table 14}

Requisitos microbiológicos para quesos de suero y quesos de proteinas de suero.

\begin{tabular}{|l|c|c|c|c|c|}
\hline \multicolumn{1}{|c|}{ Requisito } & $\mathbf{n}$ & $\mathbf{m}$ & $\mathbf{M}$ & $\mathbf{c}$ & Método de ensayo \\
\hline Enterobacteriaceas, UFC/g & 5 & $2 \times 10^{3}$ & $10^{4}$ & 1 & NTE INEN 1529-13 \\
\hline Escherichia coli, UFC/g & 5 & $<10$ & - & 0 & AOAC 991.14 \\
\hline Staphylococcus aureus UFC/g & 5 & 10 & $10^{2}$ & 1 & NTE INEN 1529-14 \\
\hline Listeria monocytogenes /25 g & 5 & ausencia & - & 0 & ISO 11290-1 \\
\hline Salmonella en 25 g & 5 & 0 & - & 0 & NTE INEN 1529-15 \\
\hline
\end{tabular}

Donde:

$\mathrm{n}=$ Número de muestras a examinar

$\mathrm{m}$ = Índice máximo permisible para identificar nivel de buena calidad.

$\mathrm{M}=$ Índice máximo permisible para identificar nivel aceptable de calidad.

$c=$ Número de muestras permisibles con resultados entre $\mathrm{m}$ y $\mathrm{M}$.

Fuente: Referencia [13].

Elaborado: INEN.

al rendimiento que se mide en el número de litros y la Unidad Bovina Adulta (UBA), se observa que la provincia de Tungurahua posee un mayor rendimiento $(8,71$ I/UBA), Cotopaxi en segundo lugar (8,05 I/UBA) y Chimborazo con el menor rendimiento 6,65 I/UBA). El acceso limitado a la tierra es la principal característica de la pequeña agricultura, la misma que se concentra en la Sierra centro de Ecuador. Así también, el empleo de mano de obra y la presencia de fallas de mercado influyen en el comportamiento de los agricultores [16]. En el año 2013 y 2014 Se colectaron 357 muestras de leche para este estudio, en los meses de enero, febrero, marzo, mayo, septiembre, octubre, noviembre y diciembre. Las muestras fueron colectadas de tanques de refrigeración 


\section{Table 15}

Requisitos fisicoquimicos para quesos de suero y quesos de proteínas de suero.

\begin{tabular}{|l|c|c|}
\hline & \multicolumn{2}{|c|}{$\begin{array}{c}\text { Grasa láctea \% (m/m) en extracto seco } \\
\text { MIN }\end{array}$} \\
\hline Queso de suero con crema & 33,0 & $<33,0$ \\
\hline Queso de suero & 10,0 & $<10,0$ \\
\hline Queso de suero descremado & -- & \multicolumn{2}{|c|}{ NTE INEN 64 } \\
\hline METODO DE ENSAYO & \multicolumn{2}{|c|}{} \\
\hline
\end{tabular}

Fuente: Referencia [13]

Elaborado: INEN.

Table 16

Descripción de las caracteristicas de la producción lechera en la zona cenro del Ecuador entre los años 2015 y 2017.

\begin{tabular}{|c|c|c|c|c|c|c|c|}
\hline \multirow{3}{*}{ Año } & \multirow{3}{*}{ Descripción } & \multicolumn{6}{|c|}{ Provincias } \\
\hline & & \multicolumn{2}{|c|}{ Cotopaxi } & \multicolumn{2}{|c|}{ Tungurahua } & \multicolumn{2}{|c|}{ Chimborazo } \\
\hline & & Cantidad & Variación( \%) & Cantidad & Variación( \%) & Cantidad & Variación( \%) \\
\hline 2016 & $\begin{array}{l}\text { Posicionamiento de } \\
\text { la Producción } \\
\text { Nacional de leche* }\end{array}$ & $7.00 \%$ & & $6.00 \%$ & & $7.00 \%$ & \\
\hline 2015 & Producción de & 529614 & & 330239 & & 405036 & \\
\hline 2016 & leche cruda & 483699 & -9 & 355679 & 8 & 458181 & 13 \\
\hline 2017 & (litros) & 514759 & 6 & 297060 & -16 & 431325 & -6 \\
\hline 2015 & Número de & 234615 & & 120199 & & 208509 & \\
\hline 1016 & cabezas de & 221960 & -5 & 126754 & 5 & 228500 & 10 \\
\hline 2017 & ganado & 254709 & 15 & 108133 & -15 & 222316 & -3 \\
\hline 2015 & Número de & 65673 & & 39505 & & 59990 & \\
\hline 2016 & vacas & 61179 & -7 & 40470 & 2 & 72524 & 21 \\
\hline 2017 & ordeñadas & 63932 & 4 & 34103 & -16 & 64846 & -11 \\
\hline
\end{tabular}

Fuente: Referencias [14, 15].

Elaborado por: INEC.

de productores organizados (49\%) y de tanques de refrigeración de productores individuales (51\%). Todos los productores de leche estaban localizados en la región central del país, en el sector de la provincia del Pichincha $\left(0^{\circ} 514 \mathrm{~N}\right.$ y $\left.78^{\circ} 612 \mathrm{O}\right)$; dentro de esta región fueron considerados dos pisos altitudinales, uno en Cayambe (Z1), ubicado a > 3000 m.s.n.m., y otro en San Miguel de los Bancos (Z2), a 1050 m.s.n.m. Z1 presentó una temperatura anual promedio entre $8-15^{\circ} \mathrm{C}$ y una humedad relativa del $65 \%$; y $\mathrm{Z} 2$ presentó una temperatura promedio de $18-24^{\circ} \mathrm{C}$ y una humedad relativa del 85\% [18]. Durante la colecta de muestras de leche se siguieron los procedimientos de referencia, utilizando frascos estériles de $50 \mathrm{ml}$ y conservante Azidiol. Las mues- tras fueron transportadas en refrigeración a $4-7^{\circ} \mathrm{C}$ al Laboratorio de Calidad de Leche de la Universidad Politécnica Salesiana [19].

De igual manera se tomó muestras más al norte de pichincha en este caso en la provincia del Carchi está ubicada al norte del callejón interandino entre los paralelos 


\section{Table 17}

Distributivo de las muestras de leche de acuerdo con los niveles de conteo de bacterias.

\begin{tabular}{cccc}
\hline Clasificación & Conteo total de bacterias (UFC/ml) & n & $\%$ \\
\hline Bajo & $<100000$ & 233 & 65,3 \\
Medio & $100000-500000$ & 68 & 19,1 \\
Alto & $500000-1^{\prime} 000000$ & 35 & 9,8 \\
Muy alto & $>1^{\prime} 000000$ & 21 & 5,9 \\
\hline
\end{tabular}

Fuente: Referencia [18]

Elaborado: Roció Contero.

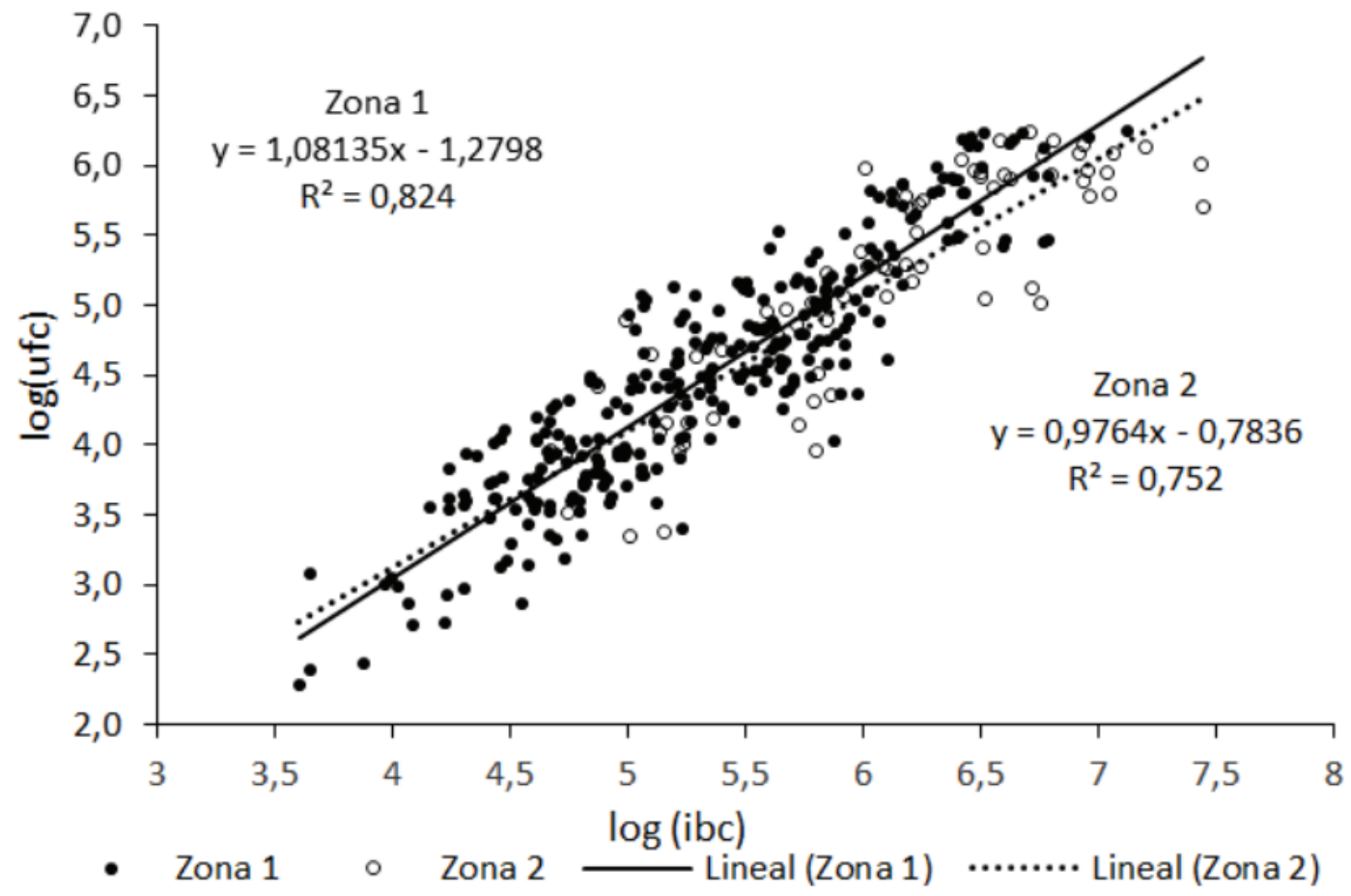

Figure 3

Distribución de regresión lineal en log (IBC/mL) y $\log (\mathrm{UFC} / \mathrm{mL})$ para zona 1 y 2. Fuente: Referencia [18]. Elaborado: Roció Contero.

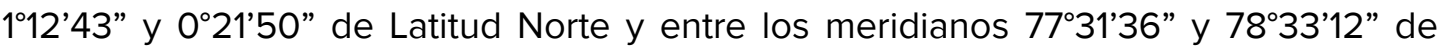
Longitud Occidental. El relieve del terreno es irregular y montañoso. Limita al norte con los ríos Carchi y San Juan en la fron- tera con Colombia, al sur con la provincia de Imbabura, al este con la provincia de Sucumbíos, y a occidente con la de Esmeraldas. Sus pisos climáticos se encuentran desde los 1.200 m.s.n.m., hasta los 4.768 m.s.n.m., y con temperaturas que oscilan entre 0 hasta los $27^{\circ} \mathrm{C}$ en las zonas fronterizas con esmeraldas. Está dividida en seis cantones incluida la capital; Bolívar, Espejo, Mira, Montufar, San Pedro de Huaca, Tulcán. Se desarrolló en la primera fase con un total de 
709 pequeños y medianos producto - res de leche, agremiados en 16 centros de acopio 4 queseras artesanales, 3 centros de acopio privados y el Centro Agrícola de Tulcán, correspondientes a 5 cantones de la provincia del Carchi, territorialmente distribuidos así: Cantón Tulcán 5 asociaciones, 1 Centro Agrícola; cantón Huaca 3 asociaciones; cantón Montufar 4 asociaciones, 3 centros de acopio, 2 queseras artesanales; cantón Espejo 2 asociaciones, 1 quesera artesanal; cantón Mira 1 asociación, 1 quesera artesanal. En el desarrollo del estudio, en la segunda fase se retiraron 2 centros de acopio privados y una asociación por problemas socio-organizativos, finalizando con 15 centros de acopio asociados, 1 centro de acopio privado, 4 queseras artesanales, sumándose en reemplazo el Centro Agrícola de Tulcán. Por lo tanto, el análisis se realizó en base a los centros que finalizaron el estudio con la segunda toma de 630 muestras [19].

\section{Table 18}

Conteo celular y bacteriano de pequeños y medianos productores asociados 5 cantones de Carchi.

\begin{tabular}{|c|c|c|c|c|c|c|c|c|c|c|}
\hline \multirow[t]{2}{*}{ Asociaciones } & \multicolumn{2}{|c|}{$\begin{array}{c}\text { Total } \\
\text { muestras }\end{array}$} & \multicolumn{4}{|c|}{$\mathrm{CCS}>500.000$} & \multicolumn{4}{|c|}{ CBT $>600.000$} \\
\hline & TM 1 & TM 2 & Toma 1 & $\%$ & Toma 2 & $\%$ & Toma 1 & $\%$ & Toma 2 & $\%$ \\
\hline Linea roja & 112 & 87 & 43 & 38.4 & 37 & 42.5 & 10 & 8.9 & 13 & 14.9 \\
\hline 20 de marzo & 13 & 10 & 5 & 38.5 & 5 & 50.0 & 2 & 15.4 & 3 & 30.0 \\
\hline Tuquer & 23 & 13 & 5 & 21.7 & 3 & 23.1 & 4 & 17.4 & 4 & 30.8 \\
\hline Pizan & 25 & 13 & 6 & 24.0 & 1 & 7.7 & 10 & 40.0 & 3 & 23.1 \\
\hline Progresista mirador & 29 & 29 & 8 & 27.6 & 7 & 24.1 & 6 & 20.7 & 5 & 17.2 \\
\hline Taya & 30 & 23 & 4 & 13.3 & 5 & 21.7 & 5 & 16.7 & 3 & 13.0 \\
\hline Avancemos juntos & 15 & 13 & 4 & 26.7 & 3 & 23.1 & 7 & 46.7 & 4 & 30.8 \\
\hline Incca promsa & 24 & 20 & 8 & 33.3 & 5 & 25.0 & 9 & 37.5 & 10 & 50.0 \\
\hline Mariscal sucre & 27 & 18 & 11 & 40.7 & 9 & 50.0 & 19 & 70.4 & 14 & 77.8 \\
\hline Chitán & 38 & 31 & 12 & 31.6 & 17 & 54.8 & 19 & 50.0 & 21 & 67.7 \\
\hline Centro agricola tulcán & 18 & 12 & 6 & 33.3 & 7 & 58.3 & 11 & 61.1 & 6 & 50.0 \\
\hline Bicundos & 42 & 16 & 15 & 35.7 & 3 & 18.8 & 26 & 61.9 & 8 & 50.0 \\
\hline Palo blanco & 10 & 9 & 3 & 30.0 & 2 & 22.2 & 3 & 30.0 & 1 & 11.1 \\
\hline Emprendedores & 18 & 15 & 7 & 38.9 & 3 & 20.0 & 8 & 44.4 & 3 & 20.0 \\
\hline San pedro & 52 & 41 & 24 & 46.2 & 16 & 39.0 & 14 & 26.9 & 11 & 26.8 \\
\hline Sendero campo fertil & 22 & 19 & 9 & 40.9 & 7 & 36.8 & 15 & 68.2 & 3 & 15.8 \\
\hline Delicia & 95 & 58 & 29 & 30.5 & 17 & 29.3 & 47 & 49.5 & 18 & 31.0 \\
\hline Q'señor & 20 & 12 & 5 & 25.0 & 4 & 33.3 & 10 & 50.0 & 8 & 66.7 \\
\hline Agroincas & 17 & 10 & 6 & 35.3 & 3 & 30.0 & 8 & 47.1 & 0 & 0.0 \\
\hline TOTAL & 630 & 449 & 210 & 33.3 & 154 & 34.3 & 233 & 37.0 & 138 & 30.7 \\
\hline
\end{tabular}

Fuente: Referencia [19].

Elaborado por: De la Cruz, Eloy Guillermo Simbaña Díaz, Paola Bonifaz, Nancy.

En Manabí se da dos sistemas de ordeño y su incidencia en la calidad higiénica de la leche que se produce en 4 cantones de la provincia de Manabí, mediante la medición de los parámetros: Calidad físico-química, perfil de ácidos grasos, y recuento 


\section{Table 19}

Prueba CTM realizada a 1094 Vacas lecheres de 210 productores 5 cantones de Carchi.

\begin{tabular}{cc}
\hline Prueba CMT & $\begin{array}{c}\text { Resultado en \% } \\
\text { (pezones afectados) }\end{array}$ \\
\hline - (Negativo) & 60.09 \\
T (trazas) & 15.05 \\
+ (Positiva nivel 1) & 15.88 \\
++ (Positiva nivel 2) & 7.07 \\
+++ (Positiva nivel 3) & 0.8 \\
Pezones perdidos & 1.12 \\
Total: & $\mathbf{1 0 0 \%}$ \\
\hline
\end{tabular}

Fuente: Referencia [19].

Elaborado por: De la Cruz, Eloy Guillermo Simbaña Díaz, Paola Bonifaz, Nancy

de células somáticas, Se analizaron las siguientes variables físicas y químicas: Acidez titulable mediante la norma técnica NTE INEN 13:1984, reductasa según la norma NTE INEN 18:1973, pH con la norma NTE INEN-ISO 10523, Densidad de la leche acorde a la técnica NTE INEN 11:1984, grasa por extracción con el método NTE INEN-ISO 2446:2013, sólidos totales y ceniza conforme lo dispone la norma NTE INEN 14:1984, proteína total mediante destilación con el método establecidos en la norma técnica NTE INEN-ISO 8968-1IDF 20-1, calcio y fósforo por el método NTE INEN-ISO 8070IIDF 119), conteo de células somáticas de acuerdo con la técnica NTE INEN-ISO 13366-1IIDF 148-1) y cromatografía de ácidos grasos siguiendo los lineamientos de la ISO 5508:1990 [20].

\subsubsection{Analisis situacional de la producción de Quesos de acuerdo a nor- mas NTE INEN}

Analisaremos algunos sectores como ha sido el comportamiendo de la produccion de Quesos de acuerdo a la produccion de leche cruda en base a parametros de las normas NTE INEN. Las microempresas del sector lácteo en Ecuador fabrican queso principalmente del tipo fresco no madurado, es decir de aquel que se debe consumir inmediatamente después de la fabricación. La desnaturalización ofrece importantes ventajas tales como el aumento del rendimiento y del valor nutritivo del queso [21] y la destrucción de bacterias tanto benéficas como perjudiciales. Rodríguez [22] plantea que la leche puede tener alteraciones físicas y pérdidas importantes del valor nutritivo cuando sufre tratamiento térmico excesivo, como por ejemplo la pérdida de lactosa a través de la reacción de Maillard, que produce sabores y colores indeseables. La disminución en el contenido disponible del aminoácido lisina es entre 1-2\% por efecto de la pasteurización y entre $2-4 \%$ por esterilización a altas temperaturas.

La pasteurización de la leche en las microempresas se realiza en forma discontinua aplicando fuego directo, o con vapor, a diferentes temperaturas. Las temperaturas más 


\section{Table 20}

Promedios de la calidad físico química de la leche en bovinos de boble propósito en cuatro cantones de Manabí.

\begin{tabular}{|c|c|c|c|c|c|c|c|c|c|c|}
\hline FACTORES & $\begin{array}{l}\text { ST } \\
(\%)\end{array}$ & $\begin{array}{l}\text { CENI- } \\
\text { ZA (\%) }\end{array}$ & $\begin{array}{c}\text { GRASA } \\
(\%)\end{array}$ & $\begin{array}{c}\text { PROTEÍ- } \\
\text { NA (\%) }\end{array}$ & $\mathrm{pH}$ & $\begin{array}{c}\text { ACIDEZ } \\
(\%)\end{array}$ & $\begin{array}{c}\text { DENSI- } \\
\text { DAD (g/ } \\
\mathrm{ml})\end{array}$ & $\begin{array}{l}\text { REDUCTA- } \\
\text { SA (horas) }\end{array}$ & $\begin{array}{l}\text { CAL- } \\
\text { CIO } \\
(\%) \\
\end{array}$ & $\begin{array}{l}\text { FOSFO- } \\
\text { RO (\%) }\end{array}$ \\
\hline \multicolumn{11}{|c|}{ FACTOR A: SIST. DE ORDEÑO } \\
\hline Manual & $12,30 \mathrm{~b}$ & $0,68 \mathrm{~b}$ & $3,13 \mathrm{~b}$ & $3,48 \mathrm{~b}$ & $6,62 \mathrm{~b}$ & $0,18 \mathrm{~b}$ & $1,03 \mathrm{a}$ & $2 \mathrm{a}$ & $0,60 \mathrm{~b}$ & $0,60 \mathrm{a}$ \\
\hline Mecánico & $12,74 \mathrm{a}$ & $0,70 \mathrm{a}$ & 3,97 a & $3,69 \mathrm{a}$ & $6,66 \mathrm{a}$ & $0,19 \mathrm{a}$ & $1,04 \mathrm{a}$ & $3 \mathrm{a}$ & $0,73 \mathrm{a}$ & 0,62 a \\
\hline \multicolumn{11}{|c|}{ FACTOR B: LOCALIDADES } \\
\hline Pedernales & $12,15 \mathrm{c}$ & $0,70 \mathrm{a}$ & $3,11 \mathrm{c}$ & $3,53 \mathrm{a}$ & $6,61 \mathrm{~b}$ & $0,17 \mathrm{~b}$ & $1,03 \mathrm{ab}$ & $3 \mathrm{a}$ & 0,94 a & $0,72 \mathrm{a}$ \\
\hline El Carmen & $12,66 \mathrm{ab}$ & $0,68 \mathrm{a}$ & $3,57 \mathrm{~b}$ & 3,57 a & $6,61 \mathrm{~b}$ & $0,17 \mathrm{~b}$ & $1,03 \mathrm{ab}$ & $3 \mathrm{a}$ & $0,98 \mathrm{a}$ & 0,71 a \\
\hline Flavio Alfaro & $12,80 \mathrm{a}$ & $0,68 \mathrm{a}$ & $4,03 \mathrm{a}$ & $3,65 \mathrm{a}$ & $6,70 \mathrm{a}$ & $0,19 \mathrm{a}$ & $1,03 \mathrm{~b}$ & $3 \mathrm{a}$ & $0,26 \mathrm{c}$ & $0,45 \mathrm{c}$ \\
\hline Bolívar & $12,46 \mathrm{~b}$ & $0,69 \mathrm{a}$ & $3,51 \mathrm{bc}$ & $3,57 \mathrm{a}$ & $6,66 \mathrm{a}$ & $0,19 \mathrm{a}$ & $1,06 \mathrm{a}$ & $3 \mathrm{a}$ & $0,47 \mathrm{~b}$ & $0,55 \mathrm{~b}$ \\
\hline \multicolumn{11}{|c|}{ INTERACCION } \\
\hline $\mathbf{T} 1=\mathbf{M a}^{*} \mathbf{P e d}$ & $11,62 \mathrm{e}$ & $0,69 \mathrm{ab}$ & $3,54 \mathrm{bc}$ & $3,67 \mathrm{a}$ & $6,55 \mathrm{~b}$ & $0,16 \mathrm{bc}$ & $1,03 \mathrm{ab}$ & $3 a b$ & $0,87 \mathrm{a}$ & $0,71 \mathrm{a}$ \\
\hline $\mathrm{T} 2=\mathrm{Ma}^{*} \mathrm{Car}$ & $11.84 \mathrm{de}$ & $0.64 \mathrm{~b}$ & $4.43 \mathrm{a}$ & $3.68 \mathrm{a}$ & $6.55 \mathrm{~b}$ & $0.15 \mathrm{c}$ & $1.03 \mathrm{~b}$ & $2 \mathrm{c}$ & $0.95 \mathrm{a}$ & $0.71 \mathrm{a}$ \\
\hline $\mathbf{T} 3=\mathrm{Ma}^{*} \mathrm{Fla}$ & $13.12 \mathrm{ab}$ & $0.68 \mathrm{ab}$ & $4.10 \mathrm{ab}$ & $3.76 \mathrm{a}$ & $6.73 \mathrm{a}$ & $0.19 \mathrm{a}$ & $1.02 \mathrm{~b}$ & $2 \mathrm{bc}$ & $0.26 \mathrm{c}$ & $0.44 \mathrm{c}$ \\
\hline $\mathrm{T} 4=\mathrm{Ma}{ }^{*} \mathrm{Bol}$ & $12.61 \mathrm{c}$ & $0.69 \mathrm{ab}$ & $3.81 \mathrm{abc}$ & $3.66 \mathrm{a}$ & $6.66 \mathrm{a}$ & $0,19 \mathrm{a}$ & $1.08 \mathrm{a}$ & $2 \mathrm{c}$ & $0.31 \mathrm{c}$ & $0.53 \mathrm{bc}$ \\
\hline $\mathbf{T} 5=\mathbf{M c}{ }^{*}$ Ped & $12.68 \mathrm{bc}$ & $0.71 \mathrm{a}$ & $2.67 \mathrm{~d}$ & $3.40 \mathrm{a}$ & $6.67 \mathrm{a}$ & $0.18 \mathrm{ab}$ & $1.03 \mathrm{ab}$ & $3 \mathrm{a}$ & $1.01 \mathrm{a}$ & $0.73 \mathrm{a}$ \\
\hline $\mathrm{T} 6=\mathrm{Mc}^{*} \mathrm{Car}$ & $13.49 \mathrm{a}$ & $0.71 \mathrm{a}$ & $2.71 \mathrm{~d}$ & $3.46 \mathrm{a}$ & $6.66 \mathrm{a}$ & $0.19 \mathrm{a}$ & $1.03 \mathrm{ab}$ & $3 \mathrm{a}$ & $1.00 \mathrm{a}$ & $0.72 \mathrm{a}$ \\
\hline $\mathrm{T} 7=\mathrm{Mc}^{*} \mathrm{Fla}$ & $12.47 \mathrm{c}$ & $0.69 \mathrm{ab}$ & $3.96 \mathrm{ab}$ & $3.55 \mathrm{a}$ & $6.66 \mathrm{a}$ & $0,20 \mathrm{a}$ & $1.03 \mathrm{~b}$ & $3 \mathrm{a}$ & $0.26 \mathrm{c}$ & $0.46 \mathrm{c}$ \\
\hline T8 $=M c^{*}$ Bo & $12.32 \mathrm{~cd}$ & $0.69 \mathrm{ab}$ & $3.20 \mathrm{~cd}$ & $3.49 \mathrm{a}$ & $6.66 \mathrm{a}$ & $0.18 \mathrm{ab}$ & $1.03 \mathrm{ab}$ & $3 a$ & $0.64 \mathrm{~b}$ & $0.58 \mathrm{~b}$ \\
\hline $\mathrm{CV} \%$ & 1,89 & 3,75 & 10,23 & 5,07 & 0,62 & 5,74 & 2,28 & 9,62 & 16,29 & 9,06 \\
\hline
\end{tabular}

Letras diferentes son significativas según la prueba de Tukey $(\mathrm{P} \leq 0.05)$

CV: Coeficiente de Variación

ST: Solidos Totales

Fuente: Referencia [20]

Elaborado: Vallejo, Christian Díaz, Raúl Morales.

utilizadas son entre 63 a $65^{\circ} \mathrm{C}$ por un tiempo de 30 min y de $72^{\circ} \mathrm{C}$ por 15 a $20 \mathrm{sec}$. Entonces es de importancia conocer cuál es el grado de la desnaturalización de las proteínas y cómo esto afecta en el rendimiento. se trataron 20 unidades experimentales desglosadas en 4 tratamientos con 5 réplicas. Los tratamientos consistieron en leche cruda o sin pasteurización, leche pasteurizadas a $65^{\circ} \mathrm{C}$ por $30 \mathrm{~min}$, leche pasteurizada a $72^{\circ} \mathrm{C}$ por $15 \mathrm{sec}$, y leche pasteurizada a punto de ebullición por $2 \mathrm{sec}$. Para cada repetición se utilizaron $10,5 \mathrm{~L}$ de leche repartida de la siguiente manera: $0,5 \mathrm{~L}$ para determinar la calidad de la materia prima, y para cada tratamiento $2,5 \mathrm{~L}$ de los cuales 0,5 L fueron utilizados para determinar por duplicado el porcentaje de proteína que permitió calcular el porcentaje de desnaturalización, y $2 \mathrm{~L}$ para elaborar el queso en el cual se determinó el peso y el porcentaje de humedad. Para la determinación de acidez, pH, prueba de alcohol y prueba de azul de metileno, se siguieron los métodos de ensayo NTE INEN 13, 973, 018 y 1500, respectivamente [23].

La producción de leche pasteurizada es distribuida a Tena, Macas, Puyo, mientras que los dos tipos de quesos son distribuidos a la ciudad de Tena y Puyo. A partir de las ventas históricas producidas en industria láctea, se realiza el pronóstico de la demanda para el año 2016 que es de 1390 kilogramos diarios en los diferentes productos que 


\section{Table 21}

Promedios del analisis fisicoquimico de la leche crudade acuerdo a NTE INEN 9:2012.

\begin{tabular}{|l|c|c|c|}
\hline \multirow{2}{*}{ PARÁMETROS } & \multirow{2}{*}{ RESULTADOS } & \multicolumn{2}{c|}{ Norma INEN 9:2012 } \\
\cline { 3 - 4 } & & Min & Max \\
\hline Densidad a $15{ }^{\circ} \mathrm{C}$ & $1,029 \pm 0,001$ & 1,029 & 1,033 \\
\hline$\%$ Grasa & $3,775 \pm 0,150$ & 3 & - \\
\hline$\%$ S. totales & $18,783 \pm 0,490$ & 11,2 & - \\
\hline$\%$ Acidez exp Ac. Láctico & $0,172 \pm 0,006$ & 0,13 & 0,18 \\
\hline $\mathrm{pH}$ & $6,850 \pm 0,050$ & - & - \\
\hline P. Crioscópico ${ }^{\circ} \mathrm{H}$ & $-0,554 \pm 0,024$ & $-0,555$ & $-0,53$ \\
\hline$\%$ Proteína & $3,384 \pm 0,179$ & 2,9 & - \\
\hline $\begin{array}{l}\text { Ensayo de reductasa (azul de } \\
\text { metileno) }\end{array}$ & Más de 3 horas & 3 & $\begin{array}{l}\text { Para leche destinada a } \\
\text { pasteurización: No se } \\
\text { coagulará por la adición de } \\
\text { un volumen igual de alcohol } \\
\text { neutro de 68\% en peso o } \\
75 \% \text { en volumen }\end{array}$ \\
\hline $\begin{array}{l}\text { Reacción de } \\
\text { proteica (prueba } \\
\text { de alcohol) }\end{array}$ & Negativo &
\end{tabular}

Fuente: Referencia [23].

Elaborado: Mejía-López, Ana Rodas, Sonia Baño, Darío.

se ofertan. Este volumen se distribuye en la siguiente forma: 90 kilogramos en quesos de mesa de 500 g, 100 kilogramos en quesos de sopa de 500 g, 1200 kilogramos en leche pasteurizada de $1000 \mathrm{~g}$. Para determinar el valor en cada proceso se tiene en cuenta las unidades que representa en cada formato un kilogramo de producto, es decir el rendimiento en litros de leche que necesita cada producto para ser elaborado. Para realizar queso de mesa se necesitan 2,6 litros de leche, para realizar un queso de sopa de $500 \mathrm{~g}$ se necesitan 3 litros de leche, para realizar una funda de leche pasteurizada se necesita 0,5 litro de leche y 0,5 litro de suero. En base al rendimiento industrial se consideran las mermas de queso y perdida de leche, se establece el índice de consumo de la materia prima recibida de los ganaderos para cada formato. El índice de consumo de leche en los procesos de producción se consideran de 0,126 por unidad de queso de mesa y 0,113 por unidad de queso de sopa. [24]

En el sector de Cayambe muy conocido por la producción de quesos Según las encuestas realizadas, se pudo apreciar que el $50 \%$ de los productores procesan entre 10.000 a $50.000 \mathrm{~L}$ de leche mensuales, el $5 \%$ entre 50.000 a $100.000 \mathrm{~L}$ y el $15 \%$ más de $100.000 \mathrm{~L}$, lo que indica que el $70 \%$ de ellos, procesan más de $10.000 \mathrm{~L}$ de leche mensuales, todos estos destinados a la producción de queso fresco pasteurizado. Tomando el criterio de Araujo [26], aproximadamente el 90\% de la leche elaborada es lactosuero, los datos evidencian que el $50 \%$ de los productores encuestados obtienen entre 9.000 a $45.000 \mathrm{~L}$ de lactosuero mensuales, el $5 \%$ entre 45.000 a $90.000 \mathrm{~L}$ y el 


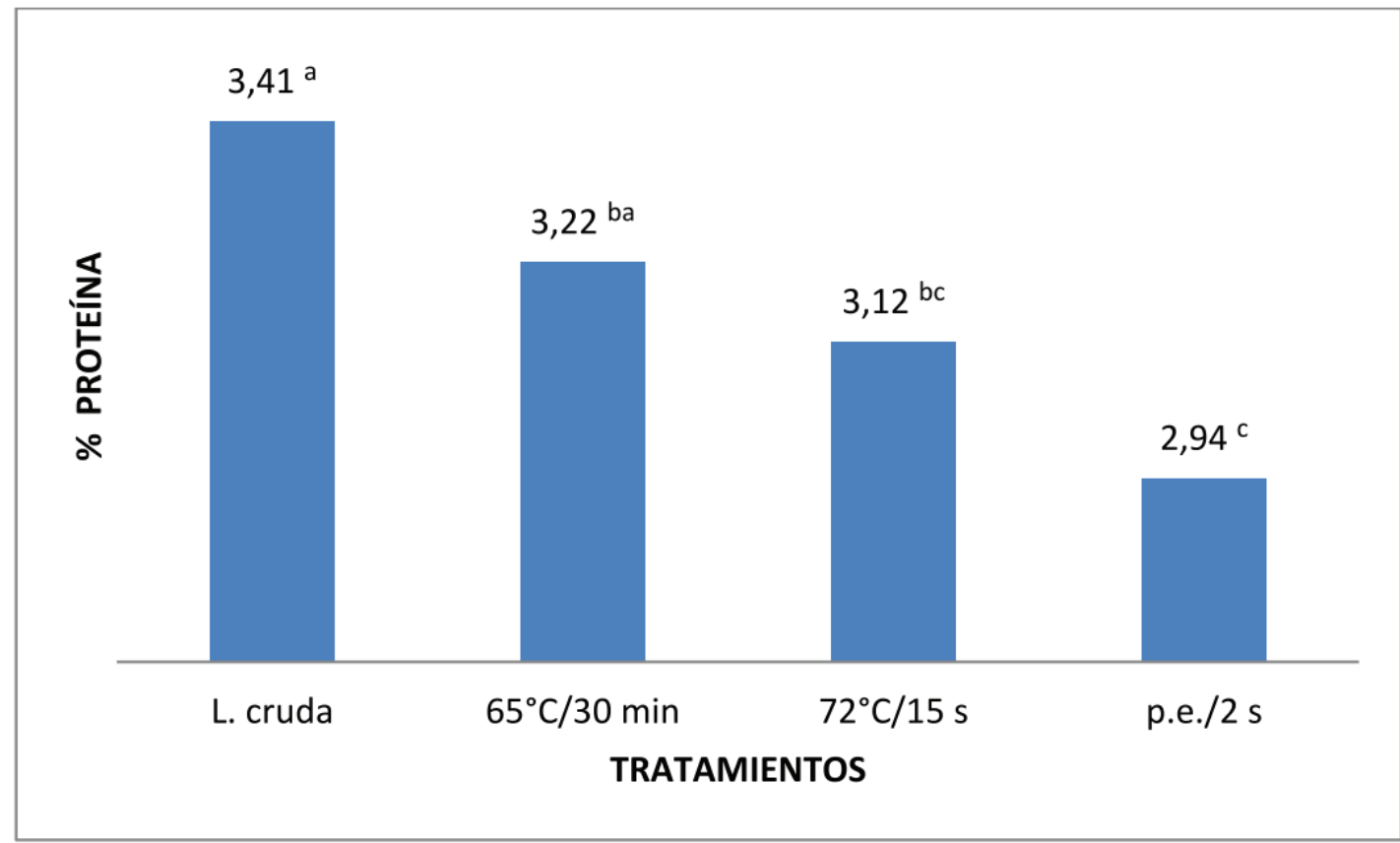

Figure 4

Promedio de porcentaje de proteina en la leche y análisis de Tukey. Fuente: Referencia [23]. Elaborado: Mejía-López, Ana Rodas, Sonia Baño, Darío.

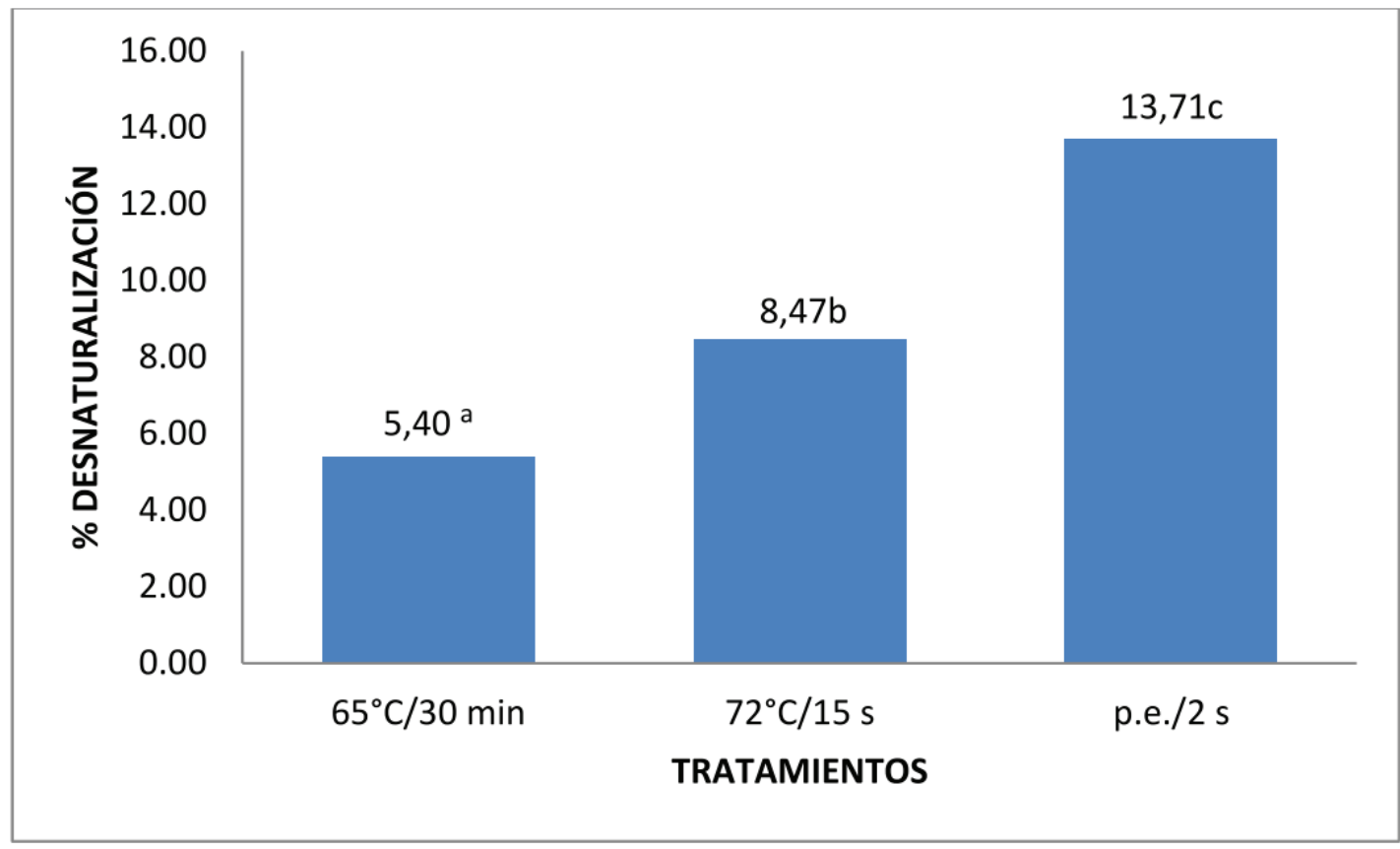

Figure 5

Porcentajes de desnaturalización de la proteína. Fuente: Referencia [23]. Elaborado: Mejía-López, Ana Rodas, Sonia Baño, Darío.

otro $5 \%$ más de 90.000 L, es decir el $70 \%$ de los productores obtiene más de 9.000 
Table 22

Relación de carga y capacidad de la industria.

\begin{tabular}{|l|c|c|c|c|c|c|}
\hline \multirow{2}{*}{ Operaciones } & \multicolumn{2}{|c|}{ Leche } & \multicolumn{2}{c|}{ Queso de mesa } & \multicolumn{2}{c|}{ Queso de sopa } \\
\cline { 2 - 7 } & $\mathbf{C i}(\mathbf{k g})$ & $\mathbf{C a}(\mathbf{h})$ & $\mathbf{C i}(\mathbf{k g})$ & $\mathbf{C a}$ (h) & $\mathbf{C i}$ (kg) & Ca (h) \\
\hline Recepción de materia prima & 1367 & 109,4 & 102 & 0,5 & 114 & 0,5 \\
\hline Filtrado & 2943 & 121,6 & 219 & 0,5 & 244 & 0,5 \\
\hline Enfriado & 3376 & 91,2 & 251 & 1,1 & & \\
\hline Pasteurizado y homogenizado & 3645 & 27,4 & 271 & 0,2 & & \\
\hline $\begin{array}{l}\text { Regulación de temperatura y } \\
\text { adicción de calcio }\end{array}$ & & & 6627 & 2,3 & & \\
\hline Cuajado & & & 1929 & 6,7 & 14127 & 1,1 \\
\hline ler corte de la cuajada & & & 25768 & 0,6 & 19643 & 0,9 \\
\hline 2do corte de la cuajada & & & 25773 & 0,6 & 18350 & 0,9 \\
\hline Batido de la cuajada & & & 15855 & 2,8 & 11035 & 2,8 \\
\hline Desuerado & & & 15855 & 2.8 & 8212 & 4 \\
\hline Adición de sal & & & 15855 & 2.8 & & \\
\hline Colocación en moldes y volteo & & & & & 16707 & 2,8 \\
\hline Baño en salmuera & & & & & 5257 & 5,7 \\
\hline Envasado & 11214 & 27,4 & 5691 & 6,7 & 5432 & 5,7 \\
\hline Prensado & & & 4179 & 6,3 & & \\
\hline Maduración & & & 5316 & 42,5 & & \\
\hline Almacenado en cuarto frío & & & 393 & 0,5 & 439 & 0,5 \\
\hline Total & & & $\mathbf{1 0 2}$ & & $\mathbf{1 1 3}$ & \\
\hline
\end{tabular}

Fuente: Referencia [24].

Elaborado: Referencia [25].

a $90.000 \mathrm{~L}$ éste subproducto lácteo mensual, resultado de la elaboración de queso fresco [27].

En la zona norte de la provincia de Manabí- Ecuador, por ser la mayor productora de queso fresco artesanal de la costa ecuatoriana, dentro de la misma los cantones: Chone, El Carmen, Flavio Alfaro y Pedernales representan el 90\% de esta producción de queso en la provincia. Para el presente estudio se consideraron los productores registrados en el proyecto de la CONEFA (Comisión Nacional de Erradicación de Fiebre Aftosa) 2016 de los cantones Chone, Flavio Alfaro, Pedernales y El Carmen) y, para lo cual se utilizó la siguiente ecuación de muestreo que cita Morales [28], para población finita indicada para universo de entre 100-5000.

En Chone la preferencia más común es el cuajo en pastilla con el $40 \%$ de uso entre la población, superior al $23 \%$ de preferencia de cuajo fresco y cuajo liofilizado las cuales o el $14 \%$ de uso que tiene el cuajo líquido. Flavio Alfaro presentó una preferencia del 


\section{Table 23}

Composición de lactosuero obtenido en veinte (20) microempresas artesanales en Cayambe.

\begin{tabular}{|c|c|c|c|c|c|c|}
\hline EM & Grasa (\%) & $\begin{array}{c}\text { Proteína } \\
\text { Total (\%) }\end{array}$ & $\begin{array}{c}\text { Lactosa } \\
(\%)\end{array}$ & $\begin{array}{c}\text { Sólidos } \\
\text { Totales } \\
(\%)\end{array}$ & $\begin{array}{c}\text { Sólidos } \\
\text { No } \\
\text { Grasos } \\
(\%) \\
\end{array}$ & pH \\
\hline E1 & $0.58 \pm 0.02 * *$ & $0.61 \pm 0.01 * *$ & $4.41 \pm 0.08^{*}$ & $6.46 \pm 0$ & $6.00 \pm 0.25$ & $6.54 \pm 0.08^{*}$ \\
\hline E2 & $0.35 \pm 0.03 * *$ & $0.51 \pm 0.07 * *$ & $4.81 \pm 0.03 *$ & $6.61 \pm 0.08^{*}$ & $6.39 \pm 0.23$ & $6.43 \pm 0.02 *$ \\
\hline E3 & $0.54 \pm 0.11 * *$ & $0.58 \pm 0.06^{* *}$ & $4.50 \pm 0.47 *$ & $6.47 \pm 0.62 *$ & $6.03 \pm 0.64$ & $6.48 \pm 0.04 *$ \\
\hline E4 & $0.36 \pm 0.08 * *$ & $0.44 \pm 0.28^{* *}$ & $4.78 \pm 0.19^{*}$ & $6.43 \pm 0.18^{*}$ & $6.16 \pm 0.03$ & $6.39 \pm 0.11 * *$ \\
\hline E5 & $0.39 \pm 0.03 * *$ & $0.63 \pm 0.02 * *$ & $4.63 \pm 0^{*}$ & $6.56 \pm 0.01 *$ & $6.29 \pm 0.14$ & $6.37 \pm 0.01 * *$ \\
\hline E6 & $0.27 \pm 0.03^{*}$ & $0.54 \pm 0.01 * *$ & $4.84 \pm 0.06^{*}$ & $6.56 \pm 0.06^{*}$ & $6.41 \pm 0.08$ & $6.45 \pm 0.08^{*}$ \\
\hline E7 & $0.39 \pm 0.07 * *$ & $0.46 \pm 0.03 * *$ & $4.81 \pm 0.06^{*}$ & $6.51 \pm 0.11 *$ & $6.23 \pm 0.18$ & $6.44 \pm 0.04 *$ \\
\hline E8 & $0.30 \pm 0 *$ & $0.30 \pm 0.01^{* *}$ & $4.73 \pm 0.01 *$ & $6.20 \pm 0.02 *$ & $6.01 \pm 0.13$ & $6.41 \pm 0.01^{*}$ \\
\hline E9 & $0.39 \pm 0.16 * *$ & $0.68 \pm 0.02 * *$ & $4.82 \pm 0.07 *$ & $6.79 \pm 0.08^{*}$ & $6.48 \pm 0.18$ & $6.48 \pm 0.03^{*}$ \\
\hline E10 & $0.64 \pm 0.01 * *$ & $0.51 \pm 0.04^{* *}$ & $4.67 \pm 0.03 *$ & $6.67 \pm 0.05^{*}$ & $6.13 \pm 0.11$ & $6.47 \pm 0.10^{*}$ \\
\hline E11 & $0.44 \pm 0.02 * *$ & $0.75 \pm 0.01 * *$ & $4.90 \pm 0.05^{*}$ & $6.93 \pm 0.13 *$ & $6.57 \pm 0.13$ & $6.53 \pm 0.01 *$ \\
\hline E12 & $0.38 \pm 0.06 * *$ & $0.58 \pm 0 * *$ & $4.70 \pm 0.03 *$ & $6.67 \pm 0.19^{*}$ & $6.29 \pm 0.25$ & $6.46 \pm 0.10^{*}$ \\
\hline E13 & $0.71 \pm 0.19 * *$ & $0.59 \pm 0.01 * *$ & $4.51 \pm 0.49^{*}$ & $6.71 \pm 0.52 *$ & $6.06 \pm 0.25$ & $6.53 \pm 0.01 *$ \\
\hline E14 & $0.41 \pm 0.08 * *$ & $0.66 \pm 0.01 * *$ & $4.82 \pm 0 *$ & $6.91 \pm 0.10^{*}$ & $6.55 \pm 0.08$ & $5.96 \pm 0.70 * *$ \\
\hline E15 & $0.61 \pm 0.08 * *$ & $0.72 \pm 0.02 * *$ & $4.82 \pm 0.03 *$ & $6.99 \pm 0.06^{*}$ & $6.47 \pm 0.15$ & $6.56 \pm 0.05^{*}$ \\
\hline E16 & $0.65 \pm 0.01 * *$ & $0.68 \pm 0.01 * *$ & $4.74 \pm 0.04 *$ & $6.91 \pm 0.03 *$ & $6.35 \pm 0.08$ & $6.52 \pm 0.06^{*}$ \\
\hline E17 & $0.38 \pm 0.03 * *$ & $0.76 \pm 0 * *$ & $4.88 \pm 0.03 *$ & $6.95 \pm 0 *$ & $6.62 \pm 0.04$ & $6.49 \pm 0 *$ \\
\hline E18 & $1.05 \pm 0.34 * *$ & $0.86 \pm 0.05^{*}$ & $4.74 \pm 0.08^{*}$ & $7.61 \pm 0.30^{*}$ & $6.64 \pm 0.08$ & $6.59 \pm 0.03 *$ \\
\hline E20 & $0.34 \pm 0.06 * *$ & $0.66 \pm 0.07 * *$ & $4.97 \pm 0.03 *$ & $6.84 \pm 0.01 *$ & $6.57 \pm 0.13$ & $6.45 \pm 0 *$ \\
\hline & $0.51 \pm 0.03 * *$ & $0.60 \pm 0.01^{* *}$ & $4.75 \pm 0.02 *$ & $6.74 \pm 0.02 *$ & $6.34 \pm 0.14$ & $6.45 \pm 0.07^{*}$ \\
\hline
\end{tabular}

Fuente: Referencia [27].

Elaborado: De la Cruz González, Eloy Guillermo Aquino Ruíz, Elena Liceth Rocha.

$61 \%$ con respecto al 18,15 y $6 \%$ que hubo para el cuajo líquido, la pastilla de cuajo y el cuajo fresco respectivamente; mientras que para Pedernales existió una preferencia mayor para la pastilla de cuajo donde un $52 \%$ de la población la eligió sobre las otras alternativas, que en ningún caso sobrepasan al 30\% de aceptación [29].

En chimborazo La ausencia de un Censo Agrario actualizado o catastro de explotaciones ganaderas ha conllevado al uso de datos secundarios, los cuales constan en el Plan de Desarrollo y Ordenamiento Territorial [30] a nivel parroquial. Identificamos 5,480 explotaciones, lecheras, donde el $42 \%$ están asentadas en la parroquia de Quimiag, el $31 \%$ en Pungalá y el $27 \%$ en Licto. La falta de información acerca de la localización y principales características de las explotaciones lecheras impide la aplicación de un muestreo probabilístico, razón por la cual, recurrimos al método de muestra teórica, o muestreo no probabilístico intencional, De esta forma, se identificaron 166 productores o ganaderos, representando el 3\% de la población, que a 
Table 24

Resultados macrobióticos de aerobios mesófilos, E. coli, coliformes totales, y Staphylococcus aureaus de acuerdo a la NTE INEN 1528:2012

\begin{tabular}{|c|c|c|c|c|}
\hline & \multicolumn{4}{|c|}{ Requisito } \\
\hline & $\begin{array}{l}\text { Aerobios } \\
\text { mesófilos } \\
\text { UFC } / g\end{array}$ & \multirow{2}{*}{\multicolumn{2}{|c|}{$\begin{array}{lc} & \text { Coliformes } \\
\text { scherichia } & \text { totales } \\
\text { oli } \mathrm{UFC} / \mathrm{g} & \mathrm{UFC} / \mathrm{g} \\
\end{array}$}} & $\begin{array}{c}\text { Staphylococcus } \\
\text { aureus UFC/g }\end{array}$ \\
\hline \multicolumn{3}{|l|}{ Empresa } & & \\
\hline E1 & $4,50 \mathrm{E}+02$ & Ausente & Ausente & Ausente \\
\hline E2 & $6,38 \mathrm{E}+04$ & 5 & $1,14 \mathrm{E}+02$ & 24 \\
\hline E3 & $6,75 \mathrm{E}+06$ & $1,90 \mathrm{E}+02$ & $2,06 \mathrm{E}+02$ & Ausente \\
\hline E4 & $7,32 \mathrm{E}+05$ & 45 & $1,55 \mathrm{E}+03$ & 12 \\
\hline E5 & $1,87 \mathrm{E}+05$ & $2,07 \mathrm{E}+02$ & $1,78 \mathrm{E}+02$ & 7 \\
\hline E6 & $6,45 \mathrm{E}+02$ & Ausente & 24 & 12 \\
\hline E7 & $6,53 \mathrm{E}+04$ & 2 & $3,86 \mathrm{E}+02$ & 10 \\
\hline E8 & $4,11 \mathrm{E}+04$ & $6,30 \mathrm{E}+02$ & $6,82 \mathrm{E}+02$ & 6 \\
\hline E9 & $6,80 \mathrm{E}+04$ & Ausente & $1,37 \mathrm{E}+03$ & 54 \\
\hline E10 & $2,76 \mathrm{E}+05$ & $1,47 \mathrm{E}+06$ & $1,40 \mathrm{E}+04$ & 10 \\
\hline E11 & $2,59 \mathrm{E}+05$ & 11 & $9,90 \mathrm{E}+02$ & 2 \\
\hline E12 & $2,15 \mathrm{E}+03$ & Ausente & 53 & 2 \\
\hline E13 & $1,42 \mathrm{E}+03$ & Ausente & 28 & 4 \\
\hline E14 & $3,06 \mathrm{E}+05$ & $1,95 \mathrm{E}+02$ & $2,87 \mathrm{E}+03$ & 4 \\
\hline E15 & $6,90 \mathrm{E}+04$ & $2,10 \mathrm{E}+03$ & $9,20 \mathrm{E}+02$ & 63 \\
\hline E16 & $4,36 \mathrm{E}+02$ & Ausente & 2 & 15 \\
\hline E17 & $1,33 \mathrm{E}+05$ & Ausente & $1,53 \mathrm{E}+03$ & 9 \\
\hline E18 & $1,08 \mathrm{E}+05$ & 30 & $3,50 \mathrm{E}+03$ & Ausente \\
\hline E19 & $5,77 \mathrm{E}+06$ & $3,30 \mathrm{E}+02$ & $2,70 \mathrm{E}+04$ & 10 \\
\hline E20 & $4,45 \mathrm{E}+04$ & 78 & $1,29 \mathrm{E}+03$ & 22 \\
\hline Promedio & $7,44 \mathrm{E}+05$ & $7,37 \mathrm{E}+04$ & $2,84 \mathrm{E}+03$ & 14 \\
\hline
\end{tabular}

Fuente: Referencia [27].

Elaborado: De la Cruz González, Eloy Guillermo Aquino Ruíz, Elena Liceth Rocha.

pesar de no responder a características de representatividad frente a la población, la literatura científica avala el uso del método no probabilístico, que a la falta de datos e información veraz de los productores, este conllevó a una primera aproximación del universo poblacional objeto de estudio, Para el caso de las industrias lácteas domiciliadas en Riobamba, los registros de control y vigilancia sanitaria revelan la presencia de 40 negocios. Sobre esta cantidad, todas ellas micro, pequeñas y medianas empresas (mipymes), seleccionamos 17 , correspondiendo a aquellas domiciliadas en las parroquias de Quimiag, Pungalá, Licto, y el núcleo urbano de Riobamba. En el trabajo 


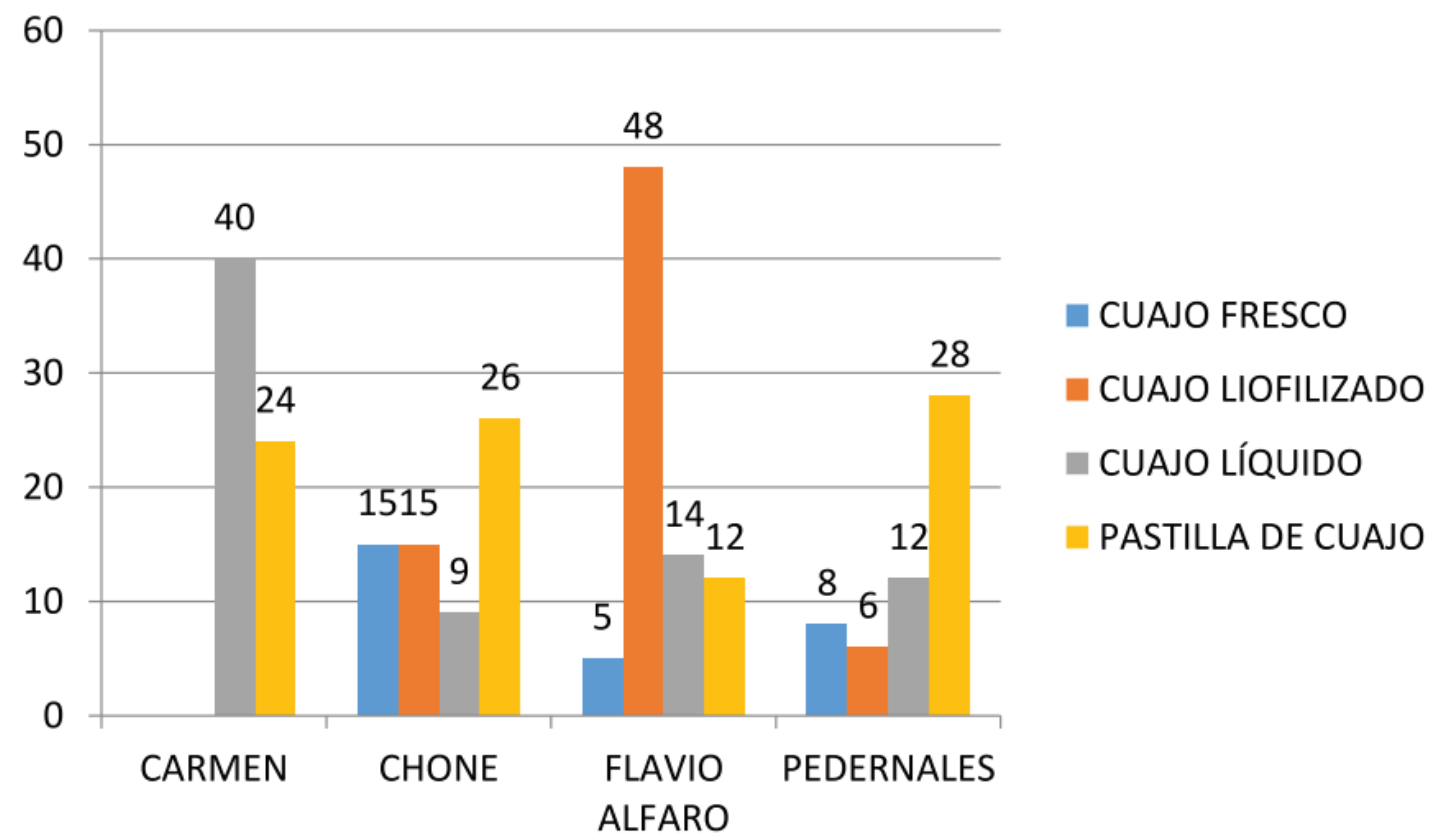

Figure 6

Regiones según el tipo de cuajo usando expresndo en fincas. Fuente: Referencia [29].

Elaborado: Arteaga Solorzano, Rudyard Antonio Mendoza Rivadeneira.

de campo fueron contactadas 16 empresas, debido a que una de estas no aceptara participar en el estudio [31], los resutados fueron los siguentes.

En el Ecuador, sobre el perfil microbiológico del queso fresco concluyeron que la carga microbiana (bacterias aerobias mesófilas, Staphylococcus aereus, coliformes totales Escherichia coli) presentes en éstos, exceden los límites permitidos por la norma NTE- INEN 1528-2012. También se ha señalado que cargas superiores a 105 UFC/g en los alimentos de Stafilococus. El Thymus vulgaris (Tomillo) es un subarbusto de la familia Lamiaceae, rica en aceite esencial, cuyo principal componente es el timol, compuesto responsable de la actividad antimicrobiana que actúa contra ciertos microrganismos de interés en alimentos como son: Staphylococcus aureus, Escherichia colí, Bacillus cereus, Proteus vulgaris, Vibrio spp, Listeria monocytogenes y Propionibacterium acnés. Se realizó un estudio desarrollado en el laboratorio de QA/QC de Alimentos de la UNACH Ecuador, Se tomo completamente al azar en dos procesos con tres repeticiones: Para el primer proceso se utilizó hojas de tomillodeshidratadas adicionadas directamente en el queso y para el segundo procesos se utilizó una infu- sión de las hojas durante el salado. Para cada proceso se trataron 48 unidades experimentales, que consis- tieron en la utilización del tomillo en 4 dosificaciones: $0 \%$ (muestra control); $1 \%$; 0,75\% y 0,5\% analizados en 4 tiempos: $A$ los 1, 8, 15 y 30 días después de la producción [32]. 


\section{Table 25}

Distribución de las industrias lacteas según el tipo de producto, y la capacidad instalada.

\begin{tabular}{|c|c|c|c|c|c|c|c|}
\hline $\begin{array}{l}\text { Capacidad } \\
\text { instalada } \\
\text { (litros/dia) }\end{array}$ & $\begin{array}{c}\text { Total de } \\
\text { industrias } \\
1\end{array}$ & $\begin{array}{c}\text { Leche a } \\
\text { granel } \\
\text { a }\end{array}$ & $\begin{array}{r}\% \\
a / 1 * 100\end{array}$ & $\begin{array}{c}\text { Leche } \\
\text { pasteurizada } \\
\text { b }\end{array}$ & $\begin{array}{c}\% \\
b / 1 * 100\end{array}$ & $\begin{array}{c}\text { Queso } \\
\text { mozzarella } \\
\text { C }\end{array}$ & $\begin{array}{c}\% \\
c / 1 * 100\end{array}$ \\
\hline$<300$ & 2 & 0 & 0 & 0 & 0 & 0 & 0 \\
\hline 300 a 799 & 3 & 0 & 0 & 0 & 0 & 0 & 0 \\
\hline 800 a 1.999 & 3 & 1 & 33 & 0 & 0 & 1 & 33 \\
\hline $\begin{array}{c}2.000 \mathrm{a} \\
4.999\end{array}$ & 3 & 1 & 33 & 0 & 0 & 0 & 0 \\
\hline $\begin{array}{c}5.000 \mathrm{a} \\
9.999\end{array}$ & 2 & 0 & 0 & 0 & 0 & 1 & 50 \\
\hline$>=10.000$ & 3 & 0 & 0 & 1 & 33 & 1 & 33 \\
\hline Total & 16 & 2 & 13 & 1 & 6 & 3 & 19 \\
\hline $\begin{array}{l}\text { Queso } \\
\text { fresco }\end{array}$ & $\%$ & Queso tierno & $\%$ & $\begin{array}{l}\text { Queso } \\
\text { maduro }\end{array}$ & $\%$ & $\begin{array}{l}\text { Yogurt } \\
\text { natural }\end{array}$ & $\%$ \\
\hline$d$ & $d / 1 * 100$ & e & $e / 1 * 100$ & $f$ & $f / 1 * 100$ & g & $\mathrm{g} / 1 * 100$ \\
\hline 2 & 100 & 0 & 0 & 0 & 0 & 0 & 0 \\
\hline 3 & 100 & 0 & 0 & 0 & 0 & 0 & 0 \\
\hline 3 & 100 & 0 & 0 & 0 & 0 & 0 & 0 \\
\hline 2 & 67 & 0 & 0 & 0 & 0 & 0 & 0 \\
\hline 2 & 100 & 1 & 50 & 1 & 50 & 1 & 50 \\
\hline 3 & 100 & 1 & 33 & 0 & 0 & 1 & 33 \\
\hline 15 & 94 & 2 & 13 & 1 & 6 & 2 & 13 \\
\hline $\begin{array}{l}\text { Yogurt con } \\
\text { frutas }\end{array}$ & $\%$ & Mantequilla & $\%$ & $\begin{array}{l}\text { Crema de } \\
\text { leche }\end{array}$ & $\%$ & $\begin{array}{l}\text { Manjar de } \\
\text { leche }\end{array}$ & $\%$ \\
\hline $\mathrm{h}$ & $\mathrm{h} / 1 * 100$ & $\mathrm{i}$ & $\mathrm{i} / 1 * 100$ & j & $\mathrm{j} / 1$ *100 & $\mathrm{k}$ & $\mathrm{k} / 1 * 100$ \\
\hline 0 & 0 & 0 & 0 & 0 & 0 & 0 & 0 \\
\hline 0 & 0 & 0 & 0 & 0 & 0 & 0 & 0 \\
\hline 1 & 33 & 0 & 0 & 0 & 0 & 1 & 33 \\
\hline 0 & 0 & 0 & 0 & 0 & 0 & 0 & 0 \\
\hline 1 & 50 & 1 & 50 & 1 & 50 & 2 & 100 \\
\hline 1 & 33 & 0 & 0 & 0 & 0 & 0 & 0 \\
\hline 3 & 19 & 1 & 6 & 1 & 6 & 3 & 19 \\
\hline
\end{tabular}

Fuente: Referencia [31].

Elaborado: Zambrano, Danny López, Edelmiro Castillo, Eddy Villacis, David.

\section{Discusión}

\subsection{Actualidad del agroindutria y la industria láctea con le presen- cia de la pandemia COVID 19}

Dependencia por ratio de importaciones: Los países del Caribe son altamente vulnerables. Por ejemplo, en Haití, más del 30\% de las importaciones totales son bienes agroalimentarios. En Antigua y Barbuda, Cuba, Santa Lucía y Barbados, las importaciones agrícolas son un $20 \%$ superiores a las importaciones totales (ver Figura 4) 10. Por otra parte, los exportadores netos de alimentos y energía se muestran menos vulnerables. En Colombia, Ecuador, Paraguay y el Estado Plurinacional de Bolivia, las importaciones agroalimentarias suman alrededor de $10 \%$ de las importaciones totales (de bienes). En los países exportadores netos de alimentos e importadores netos de 
energía, el grado de vulnerabilidad es variado, como en Belice, Guyana y Nicaragua, que son medianamente vulnerables; Perú, Chile, Brasil, México y Argentina están menos expuestos [33].

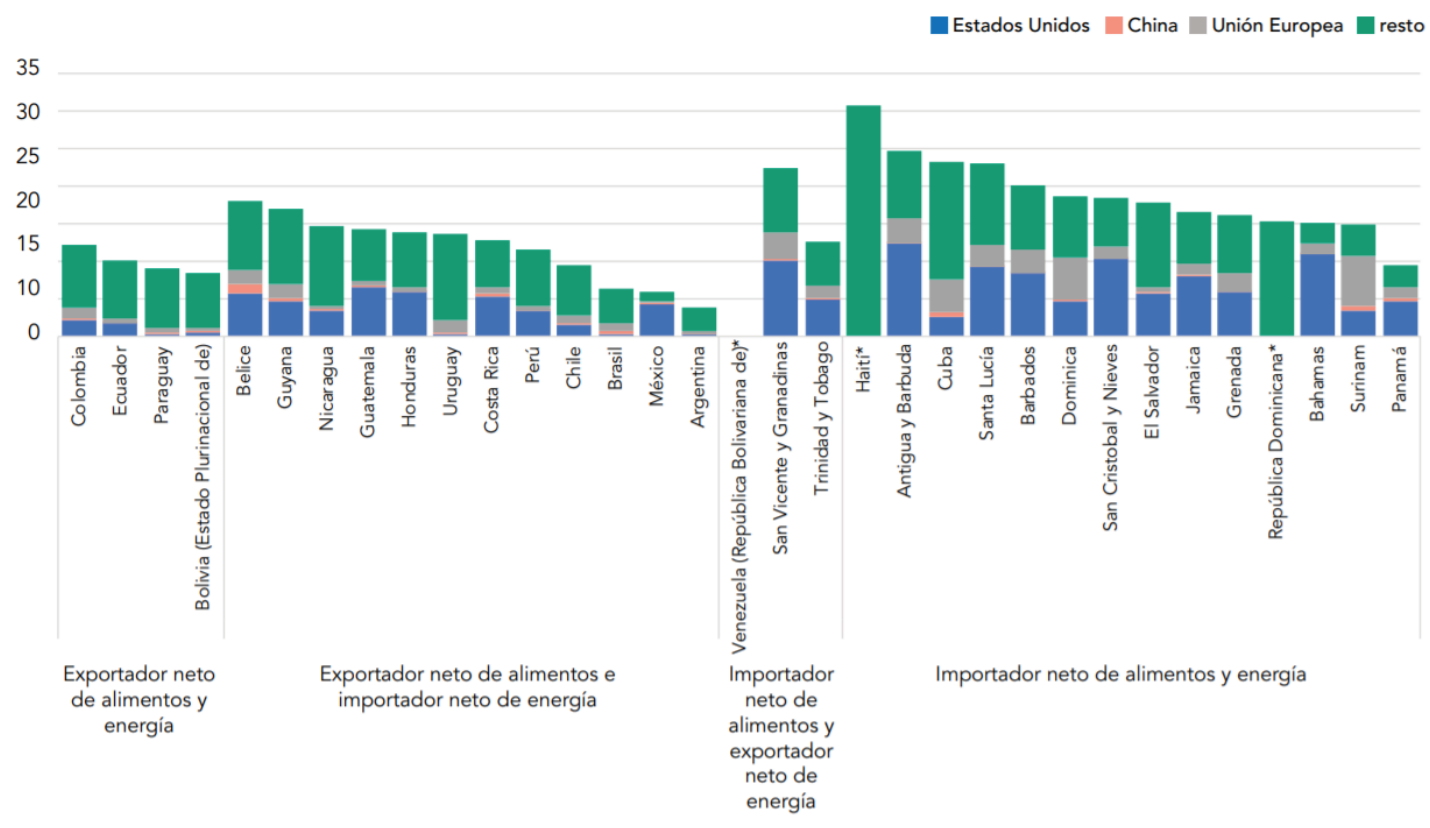

Figure 7

Dependencia de las importaciones agrícolas (\% de total de cada país/Socio). Fuente: Referencia [33]. Elaborado: FAOSTAT.

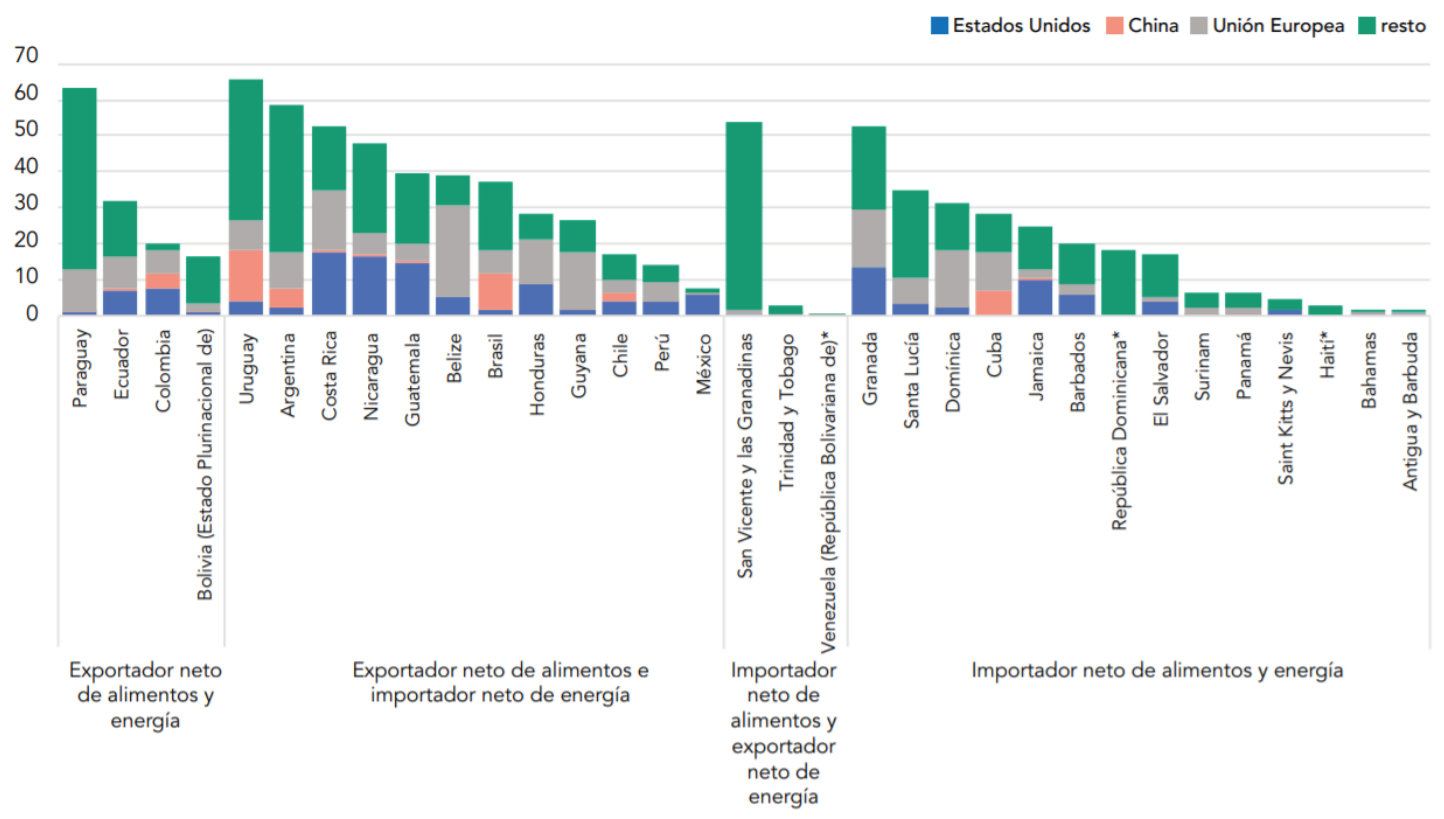

Figure 8

Dependencia de las importaciones agrícolas (\% de total de cada país/Socio). Fuente: Referencia [33]. Elaborado: FAOSTAT. 
La economía mundial vive una crisis sanitaria, humana y económica sin precedentes en el último siglo y que evoluciona continuamente. Ante la pandemia de la enfermedad por coronavirus (COVID-19), las economías se cierran y paralizan, y las sociedades entran en cuarentenas más o menos severas, medidas solo comparables a las de situaciones de guerra. Aunque no se sabe cuánto durará la crisis ni la forma que podría tener la recuperación, cuanto más rápida y contundente sea la respuesta, menores serán los efectos negativos. Algunos de los mecanismos tradicionales de mercado podrían no ser suficientes para enfrentarla debido a la interrupción de las actividades productivas y la consiguiente contracción de demanda. América Latina y el Caribe enfrenta la pandemia desde una posición más débil que la del resto del mundo. Antes de la pandemia, la CEPAL preveía que la región crecería un máximo del 1,3\% en 2020. Sin embargo, los efectos de la crisis han llevado a cambiar esa previsión y pronosticar una caída del PIB de al menos un 1,8\%. Sin embargo, no es de descartar que el desarrollo que la pandemia lleve a previsiones de contracciones de entre un 3\% y un 4\%, o incluso más. El impacto económico final dependerá de las medidas que se tomen a nivel nacional, regional y mundial, En el plano subregional, el mayor impacto lo sentirán los países de América del Sur, que se especializan en la exportación de bienes primarios y, por lo tanto, son más vulnerables a la disminución de sus precios. En cambio, el valor de las exportaciones de Centroamérica, el Caribe y México registraría una caída menor que el promedio de la región, debido a sus vínculos con los Estados Unidos y su menor exposición a la disminución de los precios de los productos primarios. Los países exportadores de petróleo experimentarán la mayor pérdida en el valor de ventas al exterior. México, la República Bolivariana de Venezuela, el Ecuador y Colombia pueden ser los países más afectados, ya que sus costos de producción son más altos que los de muchos otros productores y, por lo tanto, tienen menos capacidad para soportar un período prolongado de precios bajos [34].

En America latina la caída del 5,3\% del PIB y el aumento de 3,4 puntos porcentuales del desempleo tendrían un efecto negativo directo sobre los ingresos de los hogares y su posibilidad de contar con recursos suficientes para satisfacer las necesidades básicas. En ese contexto, la tasa de pobreza aumentaría 4,4 puntos porcentuales durante 2020 al pasar del 30,3\% al 34,7\%, lo que significa un incremento 16 Comisión Económica para América Latina y el Caribe (CEPAL) de 28,7 millones de personas en situación de pobreza [35]. En Ecuador las proyecciones del crecimiento del PIB es uno de los mas complejos para la region (vease en Figura 7), la cual generará el rompimientos en cadenas de valor y no es la excepcion como es la de la indstria lactea y sus derivados por lo cual existira un deaimineto muy considerable en produccion de leche cruda como de deribados.

Estas experiencias indican que los efectos negativos de la actual crisis del COVID19 sobre la seguridad alimentaria serán desiguales y más intensos en el caso de los países, las regiones y los grupos poblacionales que parten de una situación de mayor vulnerabilidad. En América Latina y el Caribe, la pobreza y la pobreza extrema son más elevadas en las zonas rurales, pero también la informalidad del empleo y el bajo acceso a redes de protección social, lo que genera una situación de gran vulnerabilidad. La incidencia de la pobreza no solo es mayor entre las personas que viven en áreas 


\begin{tabular}{|c|c|}
\hline & $\begin{array}{c}\text { Crecimiento del PIB } \\
2020\end{array}$ \\
\hline América Latina y el Caribe & $-5,3 \%$ \\
\hline Argentina & $-6,5 \%$ \\
\hline Bolivia (Estado Plurinacional de) & $-3 \%$ \\
\hline Brasil & $-5,2 \%$ \\
\hline Chile & $-4 \%$ \\
\hline Colombia & $-2,6 \%$ \\
\hline Ecuador & $-6,5 \%$ \\
\hline Paraguay & $-1,5 \%$ \\
\hline Perú & $-4 \%$ \\
\hline Uruguay & $-4 \%$ \\
\hline Venezuela (República Bolivariana de) & $-18 \%$ \\
\hline América del Sur & $-5,2 \%$ \\
\hline Costa Rica & $-3,6 \%$ \\
\hline Cuba & $-3.7 \%$ \\
\hline EI Salvador & $-3 \%$ \\
\hline Guatemala & $-1,3 \%$ \\
\hline Haiti & $-3,1 \%$ \\
\hline Honduras & $-2,8 \%$ \\
\hline México & $-6,5 \%$ \\
\hline Nicaragua & $-5,9 \%$ \\
\hline Panamá & $-2 \%$ \\
\hline República Dominicana & $0 \%$ \\
\hline Centroamérica y México & $-5,5 \%$ \\
\hline Centroamérica & $-2,3 \%$ \\
\hline América Latina & $-5,3 \%$ \\
\hline Antigua y Barbuda & $-7,2 \%$ \\
\hline Bahamas & $-6,8 \%$ \\
\hline Barbados & $-5,8 \%$ \\
\hline Belice & $-3.9 \%$ \\
\hline Dominica & $-3,6 \%$ \\
\hline Granada & $-7,3 \%$ \\
\hline Guyana & $56,4 \%$ \\
\hline Jamaica & $-5,3 \%$ \\
\hline Saint Kitts y Nevis & $-6,5 \%$ \\
\hline San Vicente y las Granadinas & $-3,6 \%$ \\
\hline Santa Lucia & $-8,1 \%$ \\
\hline Suriname & $-4,4 \%$ \\
\hline Trinidad y Tabago & $-5 \%$ \\
\hline El Caribe & $-2,5 \%$ \\
\hline
\end{tabular}

\section{Figure 9}

Proyecciones de crecimiento del PIB en 2020, America latina y el Caribe. Fuente: Referencia [35]. Elaborado: CEPAL.

rurales, sino también entre niños, adolescentes y jóvenes; indígenas; mujeres en edad de trabajar; personas con niveles educacionales más bajos, y quienes no alcanzan a cubrir sus necesidades básicas [33]. Por lo que sabemos que la mayor produccción de leche cruda y sus derivados estan en las zonas rurales del Ecuador por ello tendrá un decaimiento considerable de la producción. En consonancia con la evolución de 
la economía mundial, América Latina y el Caribe también ha venido experimentando una desaceleración de su crecimiento económico tras la crisis financiera mundial de 2007-2009. La desaceleración experimentada por la región fue más intensa que en otras regiones. Entre 2010 y 2019 la tasa de crecimiento del PIB regional disminuyó del $6 \%$ al $0,1 \%$. Esta desaceleración ha prolongado la trayectoria de bajo crecimiento que la región venía registrando desde fines de la década de 1970 [36] (Vease en Figura 8). Por lo Cual se espera que el panorama de América latina en especial de la agrindistria y de la industria lactea no tenga un panorama muy alentador.

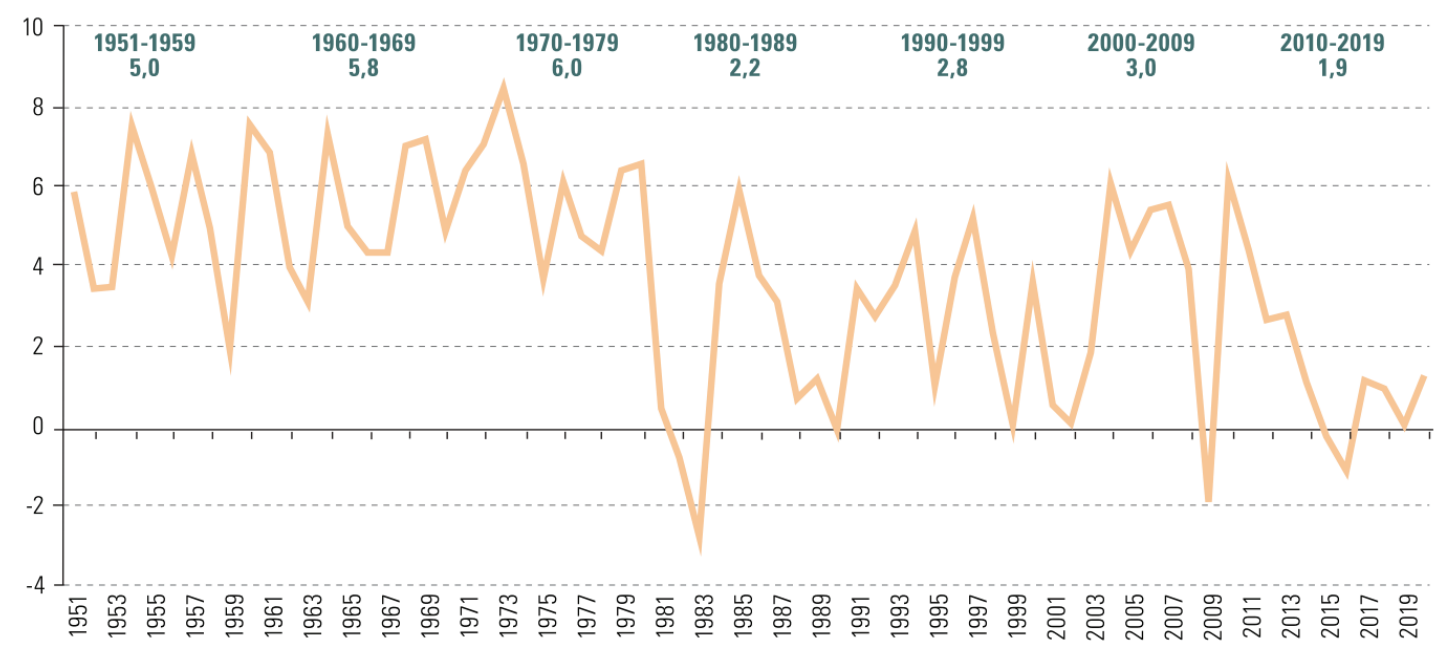

Figure 10

Tasa de crecimiento anual del PIB y promedio por decenios, 1951, 2019. Fuente: Referencia [36]. Elaborado: CEPAL.

Aunque la alimentación es un producto esencial, por lo que sus sistemas de producción no tendrían por qué verse afectados por las medidas de restricción, los confinamientos y las restricciones de circulación han comenzado a impactar los mercados y las cadenas de suministro agroalimentario [37]. Por ejemplo, los trabajadores informales se encuentran en mayor riesgo de perder sus trabajos debido a la pandemia de COVID-19. Además, los trabajadores de la economía informal tienen un mayor riesgo de enfermarse, en tanto carecen de la protección básica que los empleos del sector formal suelen ofrecer como cobertura de seguridad social [38] (véase en la Figura 9). En las zonas rurales de Ecuador la predominación es conocida por ser informal, como los partidarios y trabajadores cuidadores pastos y ganado vacuno tendrán un imparto fuerte en la perdida de empleos [39].

La provisión de alimentos constituye una cadena de valor esencial y crítica en el contexto de la pandemia COVID-19, por lo cual es imperativo mantenerla respetando los más estrictos estándares de calidad e inocuidad. Se debe reforzar al personal responsable en los principios de higiene, los métodos de saneamiento con alcance a todas las superficies de contacto directo e indirecto y los sistemas de gestión de la inocuidad, para minimizar el riesgo de transmisión del SARS-CoV2, con la premisa de adhesión estricta a las recomendaciones de las autoridades competentes de salud para todos los involucrados en dichas operaciones [40]. 


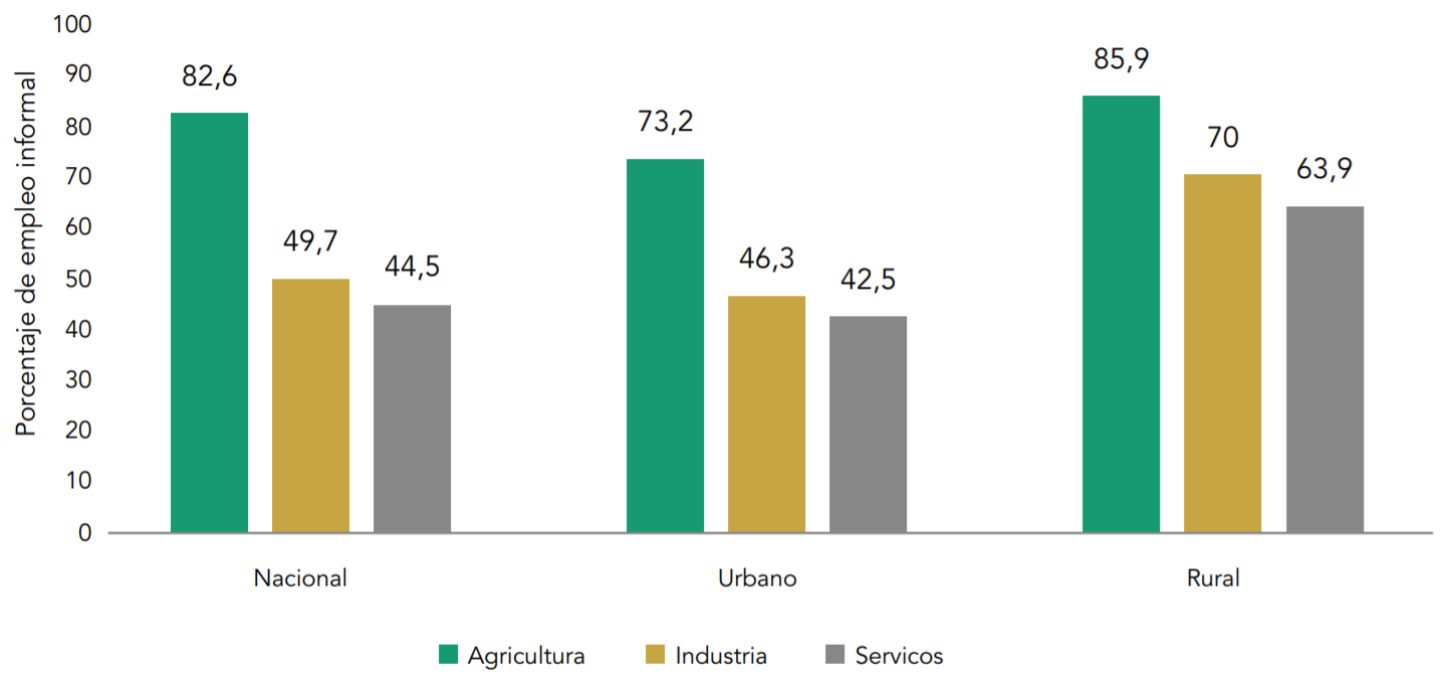

Figure 11

Tasa de empleo informal (\%) según sectores de actividad económica, en quince países de Ameria Latina* según área geográfica, 2017. Fuente: Referencia [38]. Elaborado: CEPAL.

Estamos experimentando un cambio de época. La pandemia COVID-19 se alastró por el mundo desconociendo fronteras geográficas y políticas, e hilvanó la experiencia individual y colectiva de nuestra condición de humanidad que habita una sola casa común: Nuestro planeta. Al mismo tiempo, puso al desnudo las desigualdades económicas, sociales y políticas entre los países y al interior de los mismos. Esta crisis vino a reforzar las movilizaciones ciudadanas que crecientemente exigen respuestas al gran dilema de la actualidad: 'Cómo satisfacer las necesidades del presente sin comprometer las necesidades de las generaciones futuras en un marco democrático y de justicia social' [41]. Creemos que esta transición que vivira América latina en terminos de producción de insumos primarios serán la fuente principal de sustento de muchas familias para poder sobrellevar la crisis tan agobiante que será por muchas decadas.

\section{Conclusiones}

La producción de leche cruda en el Ecuador aún se lo hace de una manera muy artesanal sin el cumplimento de Normativas Ecuatorianas NTE INEN, ya que la mayor producción es las zonas rurales, donde predomina la falta de servicios Básicos, accesibilidad a las comunidades, y los mas importante sigue existiendo índices muy altos de pobreza y falta de niveles adecuados en educación agrarias, y agroindustriales. que se verán con mayor acentuación en estas zonas después de que pase la pandemia COVID 19

El crecimiento del PIB para el 2020 del $-6,5$ que de acuerdo con CEPAL y otras entidades pronostican para Ecuador nos da una situación real de que el sistema Productivo el sector de lácteos y la industrialización de sus derivaos se verán muy afectados, por lo cual se vera un decremento en la producción, así como el consumo por la crisis económica que padecerá por mucho tiempo el Ecuador. 
Al tener un incremento de pobreza del 4,4\% promedio en los países de América latina generara que productos derivados de los lácteos se vuelvan un alimento que no podrán acceder hogares que tengan pobreza ó extrema pobreza, y la clase media de igual manera el consumo de estos productos se reducida por temas de deficiencia de generación económica.

\section{References}

[1] Manuel V, Rivera S. Presentado por especialista en estadística aplicada. 2019.

[2] Vizcarra R, Lasso R, Tapia D, Jiménez M. La leche del ecuador cilecuador. Cil Ecuador. 2015;2:2.

[3] Ortega F Cando. Pobreza multidimensional: Índice de alkire y foster para ecuador. Economía XLI. 2016;42:10-52.

[4] INEC. Ecuador en cifras. 2015 July. Available from: https://www.ecuadorencifras.gob.ec/pobreza2/.

[5] INEC 2010.

[6] Nieto C, Carlos MBLR, Monserrath MS. Influencia de la aptitud natural de uso del suelo en la pobreza y desnutrición de la población rural en la provincia de cotopaxi, sierra centro Del Ecuador. Siembra. 2017;4(1):1-20.

[7] Figueredo L. Original condiciones socio económicas como factor de emigración rural: Un análisis en la zona norte de la provincia de los ríos-ecuador. 2019;16(53):116-35.

[8] NTE INEN. Leche. Requisitos. Norma técnica ecuatoriana. 2012;(5):1-7.

[9] NTE INEN. Norma. Leche cruda. Determinación de la adulteración. Métodos de ensayo cualitativos. Norma Técnica Ecuatoriana. 2017; 1-15.

[10] INEN. Instituto ecuatoriano de normalización- norma técnica ecuatoriana. Leche pasteurizadaRequisitos. 2012;34:2-7.

[11] INEN. Norma técnica ecuatoriana. Norma general para quesos frescos no madurados. 2012: 2-7.

[12] Andino Q, Requisitos M. Norma técnica ecuatoriana. 2012.

[13] Requisitos, Proteinas D E Suero. Norma técnica ecuatoriana norma general para quesos de suero y quesos de. 2013.

[14] INEC 2016.

[15] MAGAP 2016.

[16] Crespo FC, Carrasco LM, Aimacaña NL, Chávez AC. Dinámica de los pequeños productores de leche en la sierra centro de ecuador. La Granja. 2019;30(2):103-20.

[17] Laboratorio de Sistemas de Información Geográfica-SIG- Universidad Salesiana Ecuador 2018.

[18] Bueno R. Studio En El. 2019;29(1):97-104.

[19] De la Cruz G, Guillermo E, Díaz PS, Bonifaz N. Gestión de calidad de leche de pequeños y medianos ganaderos de centros de acopio y queserías artesanales, para la mejora continua. Caso de estudio: Carchi, Ecuador. La Granja; 2018;27(1):124-36.

[20] Vallejo $C$ et al. Calidad físico-química e higuiénico sanitaria de la leche en sistemas de producción doble propósitto, manabí Ecuador. Scielo (1). 2018; 35-44.

[21] Kethireddipalli et al. 2010.

[22] Rodríguez 2002.

[23] López MA et al. Tomillo (Thymus Vulgaris) como agente antimicrobiano en la producción de queso fresco. Revista Amazónica Ciencia y Tecnología. 2017;6(1):45-54.

[24] Wahidmurni. No 主観的健康感を中心とした在宅高齢者における健康関連指標に関 する共分散構造分析. 2017;8:1-14.

[25] Sánchez 2016.

[26] Araujo 2013.

[27] De la Cruz G, Guillermo E, Ruíz ELA, Rocha DA, Bonifaz NF. Estudio de la calidad físicoquímica y microbiológica del lactosuero de queso fresco proveniente de queseras artesanales de cayambe Ecuador. Sathiri; 2018;13(2):178.

[28] Morales 2011.

[29] Solorzano A, Antonio R, Rivadeneira FAM, Zambrano RLB, Zambrano PAV. Técnicas de salado en la elaboración de queso artesanal en la zona norte de manabí. Cienciamatria. 2019;5(1):146-57.

[30] PDOT 2011. 
[31] Zambrano D, López E, Castillo E, Villacis D. El sector lácteo de Ecuador: Principales características de la cadena productiva en zonas rurales del cantón riobamba, provincia de chimborazo. Agroindustrial Science. 2017;7(1):19-32.

[32] Mejía-López A, Rodas S, Baño D. La desnaturalización de las proteínas de la leche y su influencia en el rendimiento del queso fresco." Enfoque UTE. 2017;8(2):121-30.

[33] FAO and CEPAL. Sistemas alimentarios y COVID-19 en américa latina y el caribe: Riesgos que amenazan el comercio internacional. Boletín No. 2020;3:2-17.

[34] Naciones Unidas. América latina y el caribe ante la pandemia del COVID-19efectos económicos y sociales. Informe Especial Covid-19. 2020;1:1-15.

[35] CEPAL. Informe Sobre el impacto económico en américa latina y el caribe de la enfermedad por Coronavirus (COVID-19). Publicaciones CEPAL; 2018. p. 38.

[36] Sostenible D. La Agenda 2030. La Agenda 2030. 2019;12:250-52.

[37] FAO 2020a.

[38] OIT 2020a.

[39] Sistemas alimentarios y COVID-19 en américa latina y el caribe. Sistemas alimentarios y COVID-19 en América Latina y el caribe. 2020.

[40] Espinosa EM, Aparicio ML, Rodríguez R. El saneamiento en la industria alimentaria. Relevancia ante la emergencia del Coronavirus Sars- Cov-2 Y Covid-19. Tecnología Láctea Latinoamericana. 2020;106:20_ 32.

[41] Wanderley F, Cossio HV, Benavides JP. América Latina en la encrucijada del desarrollo sostenible e inclusivo - Bolivia, Ecuador, Colombia y Perú Al Inicio Del Siglo XXI. 2020;02:25.

[42] CEPAL. COVID-19 Cómo evitar que la crisis del COVID-19 se transforme en una crisis alimentaria. acciones urgentes contra el hambre en américa latina y el caribe. 2020. 1-33. 